\title{
Review Article \\ Review of Signaling Pathways Governing MSC Osteogenic and Adipogenic Differentiation
}

\author{
Aaron W. James \\ Department of Pathology \& Laboratory Medicine, David Geffen School of Medicine, University of California, Los Angeles, \\ 10833 Le Conte Avenue, CHS A3-251, Los Angeles, CA 90077, USA
}

Correspondence should be addressed to Aaron W. James; aaronwjames1@gmail.com

Received 31 October 2013; Accepted 21 November 2013

Academic Editors: K. Bessho and G. M. Calori

Copyright (C) 2013 Aaron W. James. This is an open access article distributed under the Creative Commons Attribution License, which permits unrestricted use, distribution, and reproduction in any medium, provided the original work is properly cited.

\begin{abstract}
Mesenchymal stem cells (MSC) are multipotent cells, functioning as precursors to a variety of cell types including adipocytes, osteoblasts, and chondrocytes. Between osteogenic and adipogenic lineage commitment and differentiation, a theoretical inverse relationship exists, such that differentiation towards an osteoblast phenotype occurs at the expense of an adipocytic phenotype. This balance is regulated by numerous, intersecting signaling pathways that converge on the regulation of two main transcription factors: peroxisome proliferator-activated receptor- $\gamma(\operatorname{PPAR} \gamma)$ and Runt-related transcription factor 2 (Runx2). These two transcription factors, PPAR $\gamma$ and Runx2, are generally regarded as the master regulators of adipogenesis and osteogenesis. This review will summarize signaling pathways that govern MSC fate towards osteogenic or adipocytic differentiation. A number of signaling pathways follow the inverse balance between osteogenic and adipogenic differentiation and are generally proosteogenic/antiadipogenic stimuli. These include $\beta$-catenin dependent Wnt signaling, Hedgehog signaling, and NELL-1 signaling. However, other signaling pathways exhibit more context-dependent effects on adipogenic and osteogenic differentiation. These include bone morphogenic protein (BMP) signaling and insulin growth factor (IGF) signaling, which display both proosteogenic and proadipogenic effects. In summary, understanding those factors that govern osteogenic versus adipogenic MSC differentiation has significant implications in diverse areas of human health, from obesity to osteoporosis to regenerative medicine.
\end{abstract}

\section{Introduction}

Mesenchymal stem cells (MSC) are multipotent stromal cells capable of self-renewal and capable of multilineage mesenchymal differentiation [1]. These nonhematopoietic cells can differentiate down multiple mesenchymal lineages, including osteogenic, chondrogenic, adipogenic, myogenic, and neurogenic lineages [2] (Figure 1). Originally identified in the bone marrow, MSC are readily obtained from numerous mesenchymal tissue types, including skeletal muscle and adipose depots. In particular, adipose tissue is an attractive source for MSC isolation, as it is readily accessible with minimal morbidity by routine liposuction procedures [35]. Indeed, human adipose-derived stromal cells (or hASC) have been demonstrated to have significant potential for use in tissue engineering applications, as shown in preclinical animal models [6]. However, the uncultured stromal vascular fraction of adipose tissue represents a heterogeneous cell population that is not immediately suitable for bone formation, prompting investigators to search for alternative methods for MSC purification other than culture propagation $[5,7]$. Alternative sources for MSC derivation include nearly any vascularized tissue, from umbilical cord to oral gingiva $[8,9]$. Indeed, the perivascular origin of MSC has become an increasingly accepted theory [10-13].

MSC derived from bone marrow (BMSC) are relatively scarce in number but like all MSC have a capacity for repeated culture expansion while retaining their growth potential and multipotency [2]. BMSC typically express cell markers such as CD29, CD44, CD73, CD105, and CD166 and are negative for hematopoietic markers [2, 14]. However, it is worth noting that, with the diversity in sources and protocols for derivation, MSC cell identity remains relatively poorly defined across species, tissue type, and culture strain [15]. Upon induction and differentiation towards a specific mesenchymal lineage, the gene expression of MSC shifts until the phenotype 


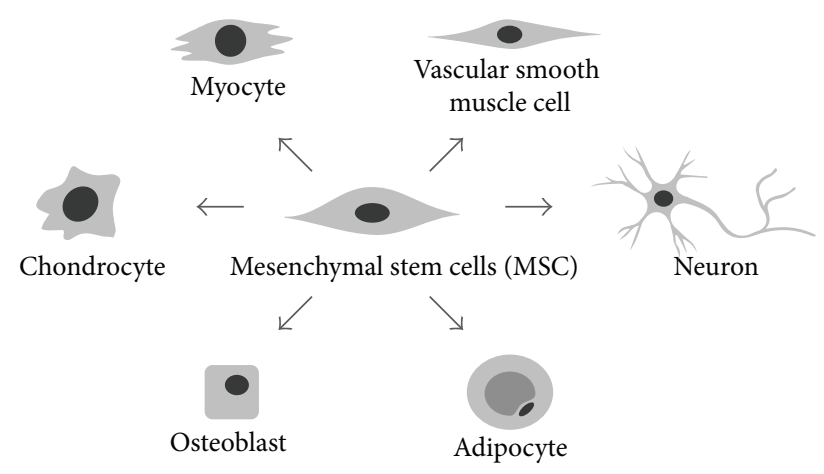

FIGURE 1: Multilineage differentiation of mesenchymal stem/stromal cells (MSC). Multipotent mesenchymal stem cells (MSC) have been derived from numerous vascularized tissue sources, including bone marrow, adipose, and skeletal muscle tissue, among others. Multilineage differentiation includes osteoblastic, chondrogenic, myogenic, smooth muscle, and neurogenic differentiation. With progressive differentiation toward a mature cell phenotype, often the capacity for differentiation down a competing lineage is lost.

is characteristic of the target cell. While MSC differentiation can be directed by multiple microenvironmental factors (such as mechanical forces [16], electrical currents [17-19], and magnetic fields [20]), this review will specifically focus on cytokine signaling that govern MSC lineage differentiation.

As mentioned, MSC function as precursors to a variety of mature mesenchymal cell types, including adipocytes. Various theoretical definitions of the process of adipocyte differentiation, or adipogenesis, have been put forth. Sinal and colleagues characterize adipogenesis in two phases: the determination phase and the terminal differentiation phase [21]. During the determination phase, multipotent MSC commit to the adipocyte lineage. Morphologically, preadipocytes have a fibroblastic phenotype and are not readily distinguishable from their MSC precursors. During the terminal differentiation phase, preadipocytes become adipocytes and acquire new functions, including lipid synthesis and storage, as well as adipocyte-specific protein production [22]. Rosen and colleagues define adipogenesis as a shift in gene expression from MSC to a phenotype that defines mature adipocytes [23], including expression of CD24, CD29, CD34, and CD36, among others [24-26]. Overall, adipogenesis is a sequentially and temporally ordered process involving multiple signaling cascades that converge at the level of peroxisome proliferatoractivated receptor- $\gamma(\operatorname{PPAR} \gamma)$ transcriptional activity $[21,23]$.

Of course, MSC also give rise to osteoblasts to form bone [2]. The process starts with commitment of osteoprogenitor cells and differentiation into pre-osteoblasts, which eventually develop into mature osteoblasts [27]. In turn, mature osteoblasts will become entombed in osteoid to become osteocytes. At its most basic level, osteoblast differentiation requires expression of the key transcription factor, Runtrelated transcription factor 2 (Runx2) [27], which will be reviewed in the coming sections. However, Runx2 expression is not sufficient for osteoblast maturation, as other transcriptions factors and extracellular signals reviewed in this chapter are also involved [28]. The development of an immature

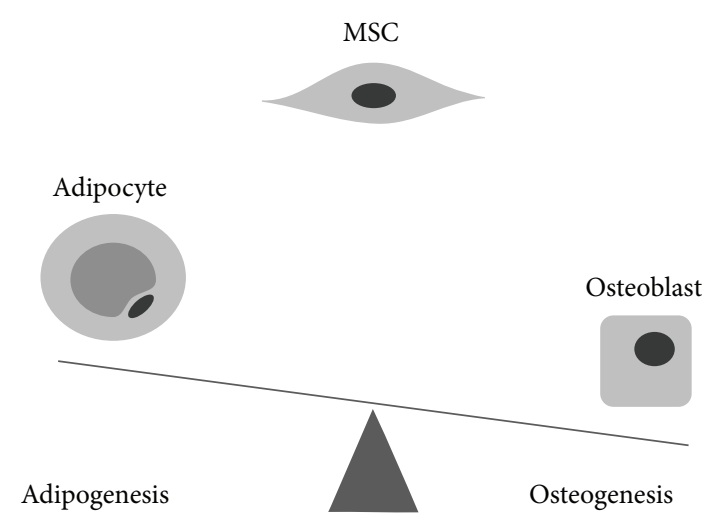

FIGURE 2: Theoretical inverse relationship between osteogenic and adipogenic programming. Multiple signaling pathways have been demonstrated to preferentially induce osteogenic programming at the expense of adipogenesis, or vice versa. In this regard, the differentiation of an MSC into either an adipocytic or osteoblastic phenotype can be theorized as a seesaw, where induction of one lineage comes at the expense of the other. However, numerous exceptions exist to this simplification.

osteoblast into a mature one can be categorized into phases of proliferation, maturation, matrix synthesis, and matrix mineralization (reviewed in [27]). Osteoblasts synthesize bone matrix to initially form bone and later function in bone remodeling and mineral metabolism [28].

The commitment and differentiation of MSC towards an adipogenic or osteogenic cell fate depend on a variety of signaling and transcription factors. A large body of experimental evidence suggests that an inverse correlation exists between adipogenesis and osteogenesis (Figure 2) [29, 30]. The evidence for an inverse relationship is primarily based on in vitro studies in which culture supplements upregulate osteogenic differentiation with associated downregulation of adipogenic differentiation, or vice versa [31-34]. Several bipotent or multipotent cell lines are commonly used. These include the pluripotent $\mathrm{C} 3 \mathrm{H} 10 \mathrm{~T} 1 / 2$ cell line and the murine BMSC line M2-10B4 [35, 36]. Several cell signaling cascades exemplify proosteogenic/antiadipocytic stimuli and will be discussed below. These include $\beta$-catenin dependent Wnt signaling (as well as $\beta$-catenin independent signaling) [37, 38], Hedgehog signaling [39, 40], and NELL-1 (NEL-like protein 1) signaling [41, 42]. Dissimilarly, various signaling cascades demonstrate positive regulation of both osteogenesis and adipogenesis. Perhaps the most clinically relevant examples are bone morphogenetic proteins (BMPs), of which BMP-2 and BMP-7 are available for orthopaedic application $[43,44]$. While the majority of BMPs promotes osteogenic commitment and differentiation of MSC $[45,46]$, BMPs also demonstrate proadipogenic effects $[47,48]$. Insulinlike growth factor (IGF) signaling likewise demonstrates dual proosteogenic/proadipogenic effects. This review will sequentially discuss the effects of these diverse signaling cascades that coordinately govern MSC osteogenesis and adipogenesis. 


\section{Control of Adipogenesis and Osteogenesis by Transcription Factor Activity: Runx2 and PPAR $\gamma$}

Signaling cascades which promote MSC osteogenic and/or adipogenic lineage differentiation generally converge on two key transcription factors: $\operatorname{PAAR} \gamma$ and Runx2. PPAR $\gamma$ is generally considered the master regulator of adipogenesis and also has well-described anti-osteoblastogenic effects. Likewise, Runx2 is regarded as the master regulator of osteogenesis. Together, they are in large part responsible for mediating the effects of various cytokines in determination of adipogenic versus osteogenic MSC differentiation. Typically, increased expression of one transcription factor is associated with downregulation of the other [49-52]. Of course, a number of other key transcriptional factors exert effects independent and in association with Runx 2 and PPAR $\gamma$. For example, Osterix and CCAAT/enhancer-binding family of proteins (C/EBP) play important adjunctive roles (see $[53,54]$ for a comprehensive review of the osteogenic and adipogenic functions of Osterix and C/EBP).

\section{The Master Osteogenic Transcription Factor, Runx2}

Originally identified as the binding site for polyomavirus enhancer binding protein (PEBP), Runx was later identified as the Moloney murine leukemia virus enhancer core binding protein [55]. The Runx family consists of three distinct proteins: Runxl-3, all of which are comprised of a varying $\alpha$ subunit with the same $\beta$ subunit $[56,57]$. In order to bind to DNA, Runx proteins must form a heterodimer with transcriptional coactivator core binding factor $\beta(\operatorname{Cbf} \beta)$, a cotranscription factor [56]. The DNA binding domain of the Runx family, known as Runt, is homologous to the Runt sequence in Drosophila. Members of the Runx family have various roles in determining stem cell commitment; Runxl determines hematopoietic stem cell differentiation [58], Runx 2 determines osteoblastic and chondrogenic cell differentiation [59], and Runx3 has roles in epithelial differentiation, neurogenesis, and chondrocyte differentiation $[60,61]$. Runx has also been postulated as both an oncogene and tumor suppressor: Runx family loss of function seems to be a key event in certain myeloid, lymphoid, and epithelial cancers [62, 63]. Retroviral overexpression of Runx2 has demonstrated oncogenic functions [64]. However, data does suggest that Runx3 acts as a tumor suppressor, as it is methylated and downregulated in cancer derived cell lines [65-68]. As the Runx family is structurally similar, it is possible that tissue-specific Runx activity allows for its complex role in carcinogenesis. In regard to osteogenic differentiation, Runx 2 activates and regulates osteogenesis as the targeted gene of many signaling pathways, including but not limited to transforming growth factor-beta 1 (TGF- $\beta 1$ ), BMP, Wingless type (Wnt), Hedgehog (HH), and (Nel)-like protein type 1 (NELL-1) [69-71]. Mice with a homozygous mutation for Cbfa-1 deficiency (Runx $2^{-/-}$) have an absence of differentiated osteoblasts and bone and die shortly after birth [72]. Such Runx2 null phenotypes cannot be rescued by the overexpression of other osteogenic factors, although the cleidocranial dysplasia-like phenotype of $R u n \times 2^{+/-}$mice can be partially rescued [73, 74]. While Runx2 is not a key regulator of adipocyte differentiation, its function in promoting osteogenesis may subvert potential adipocyte lineage differentiation in MSC.

\section{The Master Adipogenic Transcription Factor, PPAR $\gamma$}

Peroxisome proliferator-activated receptors are members of the steroid/thyroid hormone receptor gene superfamily [75]. Initially named for PPAR $\alpha$ [76], subsequent structural analogs PPAR $\delta$ and PPAR $\gamma$ were since discovered. All three PPARs are found in mammals and are activated by polyunsaturated fatty acids [77], interacting with binding sites on targeted genes by forming heterodimers with the retinoid $\mathrm{X}$ receptor (RXR) in order to recruit transcriptional coactivator proteins [78]. While both PPAR $\alpha$ and PPAR $\delta$ are expressed during adipogenesis, PPAR $\gamma$ is adipocyte restricted and more rapidly increases in expression during early adipogenesis [79, 80]. PPAR $\gamma$ is expressed during adipogenesis as two isoforms, $\operatorname{PPAR} \gamma 1$ and PPAR $\gamma 2$, the latter being predominant in adipose tissue [21]. PPAR $\gamma 1$ is expressed at lower levels in adipose tissue among other tissues, including breast and prostatic tissue [81-83]. PPAR $\gamma$ is principally regarded as the master regulator of adipogenesis, for no other factor can rescue adipocyte formation in the event of PPAR $\gamma$ knockout, and generally all proadipogenic cell signaling pathways converge with PPAR $\gamma$ [84].

It is currently believed that a ligand-dependent activation of PPAR $\gamma$ must occur for any proadipogenic effects. Even then, the ligand is only necessary in the commitment phase for the adipocyte lineage, whereas PPAR $\gamma$ expression is necessary for both commitment and differentiation phases $[84,85]$. One study demonstrated that differentiation of nonadipogenic fibroblasts required PPAR $\gamma$ activation through exposure to an exogenous ligand. By contrast, preadipocytes were able to continue with adipogenic differentiation without exposure to ligand [84]. One such set of ligands for PPAR $\gamma$ is thiazolidinediones (TZDs), which are potent PPAR $\gamma$ agonist among several other derivatives of polyunsaturated acids [86]. Recently, there have been several endogenous molecules derived from fatty acids found to bind and activate PPAR $\gamma$, although induced adipogenesis $[84,85]$. Moreover, recent studies show that ectopic expression of a mutant form of PPAR $\gamma$ without functional ligand-binding domains was able to support adipocyte differentiation [87], which inserts some doubt into the absolute requirement for $\operatorname{PPAR} \gamma$ ligand activation.

Studies from genetic manipulation of PPAR $\gamma$ in mice have confirmed its central role in adipogenic differentiation. Cells derived from PPAR $\gamma^{+/-}$mice demonstrate a reduced ability to differentiate into adipocytes [84]. PPAR $\gamma$-deficient embryonic stem cells fail to differentiate into adipocytes and instead differentiate into osteoblasts. Additionally, PPAR $\gamma^{+/-}$ mice have demonstrated increased bone mass with increased 


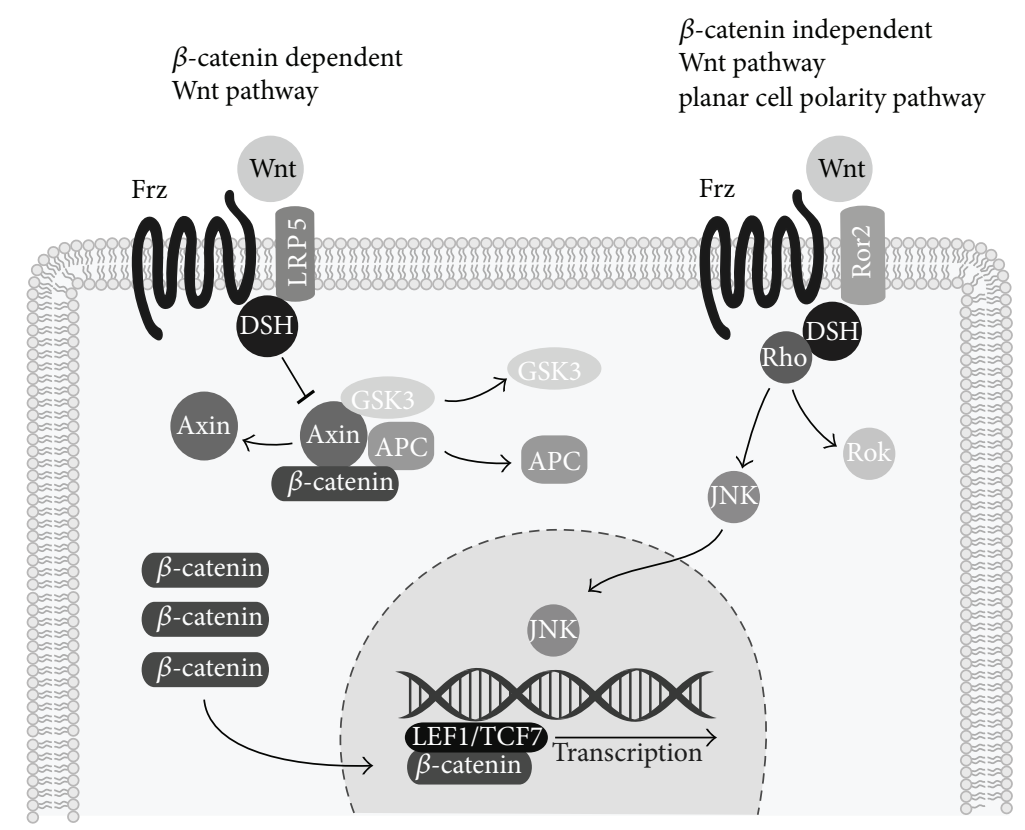

FIgURE 3: Schematic of $\beta$-catenin dependent and independent Wnt signaling pathways. Wnt signaling transduction occurs via $\beta$-catenin dependent or $\beta$-catenin independent signaling pathways. In $\beta$-catenin dependent signaling, extracellular Wnt ligands bind to the LRP5Frizzled (Frz) complex to activate intracellular disheveled (DSH). This subsequently inhibits the intracellular complex comprised of axin, glycogen synthase kinase 3 (GSK3), and adenomatosis polyposis coli (APC) protein. This inhibits the cytosolic degradation of $\beta$-catenin, which accumulates and is free to enter the nucleus to heterodimerize with lymphoid enhancer-binding factor/T cell factor (LEF/TCF1) and mediate effects of gene transcription. Under the $\beta$-catenin independent signaling pathway, a similar transmembrane complex forms between Wnt, Frz, DSH, and Ror2 and activates secondary messengers.

osteoblastogenesis, while having a marked decrease in fat stores [84]. Similarly, mice with mutation in PPAR $\gamma 2$ have decreased expression of both PPAR $\gamma 1$ and PPAR $\gamma 2$ in white adipose tissue, while exhibiting increased bone formation [47]. In another approach, selective deletion of PPAR $\gamma$ in murine adipose tissue led to a loss of both brown and white adipocytes [22].

There is much evidence supporting the anti-osteoblastogenic and proadipogenic properties of $\operatorname{PPAR} \gamma$. Several PPAR $\gamma$ agonists/ligands, namely, TZD rosiglitazone and 15deoxy-delta $(12,14)-\mathrm{PGJ}_{2}$, promote BMSC adipogenesis while inhibiting osteogenesis [88, 89]. However, not all agonists obtain this effect, as it depends on affinity of the ligand. For example, the partial agonist GW0072 inhibits MSC osteogenesis without necessarily affecting adipogenesis. In contrast, 9-hydroxyoctadecadienoic acid stimulates adipogenesis while not affecting osteoblastogenesis [88]. A similar pattern is seen in vivo, where chronic treatment of mice with low-affinity TZD troglitazone induces increased bone marrow adipocytes, without affecting bone mass [90]. Conversely, treatment with high-affinity TZD rosiglitazone decreases bone mineral density, rate of bone formation, and trabecular bone volume in addition to upregulating bone marrow adiposity [90, 91]. This inhibition of osteogenesis by high-affinity rosiglitazone was also associated with suppression of osteogenic transcription factors, including Runx2 [89]. Low-affinity agonist, netoglitazone, weakly inhibited osteoblastogenesis while inducing adipogenesis in vitro in a PPAR $\gamma 2$-dependent manner [89]. In vivo, neglitazone did not demonstrate an effect on bone, with unaffected expression levels of Runx2 [89].

\section{Control of Adipogenesis and Osteogenesis by Wnt Signaling}

Over the course of the past several decades, wingless-type MMTV integration site (Wnt) signaling has been identified to play an essential role in cell fate determination, proliferation, and differentiation [92, 93]. Dysregulation/hyperactivation of Wnt signaling is associated with numerous diseases such as neurodegeneration [94], gastrointestinal cancers [95], and osteoporosis [92]. To date, over nineteen Wnt receptors and coreceptors have been identified throughout seven families of proteins [93]. Collectively, Wnt signaling has demonstrated both proosteogenic and antiadipogenic activities, through both canonical ( $\beta$-catenin dependent) and noncanonical $(\beta$ catenin independent) pathways (Figure 3 ).

The $\beta$-catenin dependent pathway initiates with the binding of extracellular Wnt ligands to the seven-pass transmembrane frizzled receptors (Frz) expressed at the cell surface [96]. This induces complex formation with transmembrane low-density lipoprotein receptor (LRP5/6) coreceptor, as well as intracellular proteins of the disheveled (DSH) family [97]. The resulting activation of DSH then functions to inhibit a second, intracellular complex comprised of axin, glycogen synthase kinase 3 (GSK3), and adenomatosis polyposis 
coli (APC) protein (Figure 3). GSK3 normally phosphorylates $\beta$-catenin, promoting its degradation. Wnt stimulation inhibits the Axin/GSK3/APC complex, and $\beta$-catenin accumulates rather than being degraded, and levels of nuclear $\beta$ catenin increase. Once inside the nucleus, $\beta$-catenin can heterodimerize with lymphoid enhancer-binding factor/T cell factor [97]. Ultimately, $\beta$-catenin dependent Wnt signaling elicits gene transcriptional activity to influence MSC lineage determination [98] (see [92] for a more comprehensive review). While the noncanonical Wnt pathway is similar in that it involves extracellular Wnt binding to frizzled receptors (Frz) and DSH downstream, it otherwise diverges to mediate its effects through a $\beta$-catenin independent manner [99-101]. Please see [102] for a more detailed review of noncanonical Wnt signaling.

Canonical Wnt signaling has well-established effects on bone mass in both animal models and human patients. LRP5 mutational studies first identified a critical role for Wnt signaling in bone maintenance [103]. LRP5 loss-of-function mutations cause pseudo-glioma syndrome, characterized by a low bone mass phenotype. Conversely, LRP5 gain-offunction mutations result in a high bone mass phenotype [104-106]. A direct role for $\beta$-catenin in regulating osteoblast and osteoclast activity has been repeatedly observed [107]. For example, in mesenchymal osteoblastic precursors, $\beta$ catenin deficiency leads to arrest of osteoblast development at an early stage and consequent embryonic skeletal defects [107-110]. Similarly, in committed osteoblasts, $\beta$-catenin deficiency results in impaired maturation and mineralization [111, 112]. As well, Wnt/ $\beta$-catenin signaling activity in both mature and osteoblastic precursors leads to altered OPG/RANKL elaboration and secondary reductions in osteoclast activity and bone resorption [113, 114]. Accordingly, current clinical applications for osteoporosis target Wnt inhibitors to stimulate formation of new bone and inhibit bone resorption, or so-called "inhibitors to Wnt inhibitors." Currently targeted Wnt signaling antagonists include Sclerostin (SOST) and Dickkopf-1 (DKK1) [115]. Expectedly, inhibition of these antagonists, via anti-SOST and anti-DKK1, respectively, has been shown to stimulate bone formation and increase bone mineral density, with phase II clinical trials (for anti-SOST) and preclinical trials (for anti-DKK1) underway [116-118]

Various members of the Wnt signaling family have been identified to inhibit the early stages of adipogenesis [119]. For example, WNT10B has been shown to maintain 3T3-L1 preadipocytes in an undifferentiated state via inhibition of PPAR $\gamma$ and C/EBP- $\alpha$ [120-122]. Similarly, activation of $\beta$ catenin via ectopic expression of Wntl also leads to direct suppression of PPAR $\gamma$ and prevention of 3T3-L1 cell adipogenic differentiation $[120,121]$. Interestingly, this negative inhibition is reciprocal, in that upregulation of PPAR $\gamma$ functions to inhibit $\beta$-catenin signaling $[120,121,123]$. Conversely, inhibition of $\mathrm{Wnt} / \beta$-catenin signaling via treatment with DKK family proteins positively regulates adipogenesis [119, 120, 124]. Further studies suggest that the canonical ligand Wnt3a, among several others, inhibits activation of both PPAR $\gamma$ and $\mathrm{C} / \mathrm{EBP} \alpha$ in order to elicit its antiadipogenic effects [125]. However, while PPAR $\gamma$ upregulation may negatively regulate Wnt/ $\beta$-catenin signaling, overexpression of PPAR $\gamma$ and/or C/EBP $\alpha$ is not sufficient in rescuing Wnt/ $\beta$-cateninmediated inhibition of adipogenesis $[21,125]$.

In general, Wnt $/ \beta$-catenin signaling pathway activation follows the inverse pattern between the induction of MSC osteogenic and adipogenic differentiation. The activation of Wnt $/ \beta$-catenin, via lithium chloride, for instance, inhibits GSK3b, which results in general in both the promotion osteogenesis and the suppression of adipogenesis [126, 127]. Similarly, Wnt10b stimulates osteogenesis in vivo to increase bone mass while blocking adipogenesis in preadipocytes in vitro via stabilization of free cystolic $\beta$-catenin $[120,124,128]$. Other canonical Wnt ligands, such as Wnt6 and Wnt10a, exhibit similar effects in stimulating osteogenesis while also inhibiting adipogenesis [129]. Not surprisingly, disruption of Wnt/ $\beta$-catenin impairs osteogenesis in vitro [111, 112] while increasing adipogenesis both in vitro and in vivo $[120,124$, 130]. Moreover, inhibitors of the Wnt $/ \beta$-catenin pathway also demonstrate consistency with this inverse relationship between osteo- and adipogenic differentiation. DKK1, for instance, which is secreted by preadipocyte cells, inhibits osteogenesis while promoting adipogenesis in vitro [131]. The inverse relationship carries over to the noncanonical branch of Wnt signaling as well. Wnt5a, for instance, has been shown to suppress proadipogenic PPAR $\gamma$ transactivation when coinduced with proosteogenic Runx2 in MSC [21, 132]. Thus, seen across multiple ligands and inhibitors, Wnt signaling generally exerts proosteogenic and antiadipogenic effects in both canonical or noncanonical signal transduction pathways.

\section{Control of Adipogenesis and Osteogenesis by Hedgehog Signaling}

Since its original discovery in Drosophila, the Hedgehog $(\mathrm{HH})$ protein family has been identified in all vertebrates and classified into three structural homologues: Sonic Hedgehog (SHH), Indian Hedgehog (IHH), and Desert Hedgehog (DHH). DHH expression is typically limited to male reproductive tract [133] and will not be further discussed. SHH and IHH are critical during embryological development. In particular, SHH plays a key role during skeletogenesis, involved in patterning of the axial, appendicular, and facial skeleton $[134,135]$. Closely related to SHH through gene duplication, IHH regulates both chondrogenesis and endochondral bone formation [136]. In fact, disruption of $\mathrm{HH}$ signaling results in severe skeletal abnormalities, the most common of which is holoprosencephaly [137]. In regulation of stem cells, $\mathrm{SHH}$ is a critical moderator of cell differentiation, as it demonstrates proosteogenic and antiadipogenic properties in multiple MSC types [39].

All three HH morphogens follow the same, highly conserved HH signaling pathway (Figure 4). First, the insoluble $\mathrm{HH}$ polypeptide precursor undergoes conversion into a soluble, multimeric form capable of diffusing across the cell membrane. This is then autocatalytically processed from a $45 \mathrm{kD}$ to a $19 \mathrm{kD}$ protein, with modifications for a cholesterol moiety at the C-terminal and palmitate at the $\mathrm{N}$-terminal [138]. Subsequently, the modified HH morphogen is secreted from the cell via Dispatched, a large transmembrane protein, 


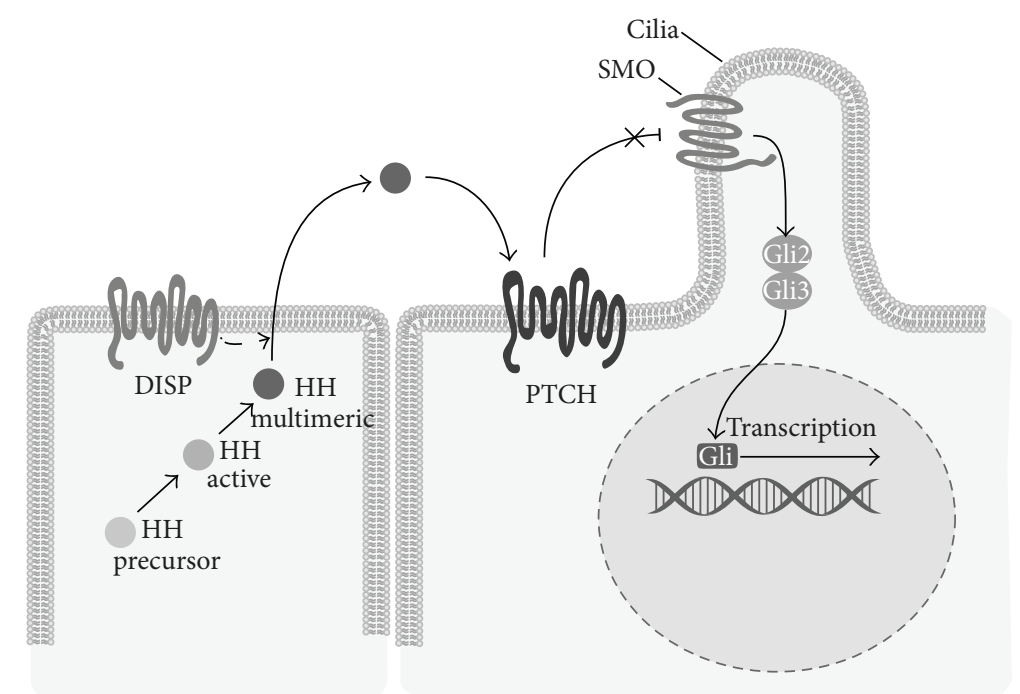

FIGURE 4: Schematic of Hedgehog signaling pathway. The initially insoluble Hedgehog (HH) ligand precursor undergoes a series of intracellular modifications before reaching an active, multimeric form. Following release from the membrane by Dispatched (DISP), the morphogen binds to Patched (PTCH), which releases Smoothened (SMO) from constitutive inhibition by PTCH. This activates the Gli2/3 complex, which goes on to promote gene expression of Glil, while repressing the transcriptional repressor Gli3.

after which it binds to the receptor Patched (PTCH), a 12-pass transmembrane protein, on the receiving cell. This binding to PTCH relinquishes Smoothened (SMO), a 7-pass transmembrane protein, from PTCH suppression, thereby enabling activation of the glioblastoma gene products (Gli) family of transcription factors (Glil-3). Since Glil is a target gene of the $\mathrm{HH}$ pathway, it is used as a reliable marker for $\mathrm{HH}$ signaling activity [84]. It is important to note that $\mathrm{HH}$ signal transduction occurs at the primary cilia and that intraflagellar transport (IFT) proteins are required to preserve cilia during $\mathrm{HH}$ signaling [135]. Accordingly, these IFT proteins are essential in transferring transmembrane proteins $\mathrm{PTCH}$ and $\mathrm{SMO}$, as movement through the cilium is required to upregulate genes targeted by $\mathrm{HH}$ signaling [84]. While being not fully understood, it is currently believed that $\mathrm{HH}$ signal transduction is mainly mediated though the Gli transcription factors, and that they are responsible for $\mathrm{HH}$ induced lineage commitment during MSC differentiation.

The antiadipogenic potential of $\mathrm{HH}$ signaling in MSC has been observed across a variety of adipocyte and multipotent cell lineages. Generally, adipogenesis in MSC, as it relates to $\mathrm{HH}$ signaling, occurs as a result of decreased Gli1, Gli2, Gli3, and PTCH expression [40]. Conversely, when the HH pathway is upregulated via SMO-activated inducer of $\mathrm{HH}$ signaling, such as purmorphamine [139], there is a significant decrease in adipocyte-specific markers: adipocyte fatty acid binding protein, adipsin, CD36, adiponectin, and leptin. Through the inhibition of adipogenic genes, $\mathrm{HH}$ signaling ultimately decreases sensitivity to insulin, which in turn reduces the expression of adipogenic transcription factors, $\mathrm{C} / \mathrm{EBP} \alpha$ and PPAR $\gamma$ [40]. Moreover, in vitro studies evaluating RNAi scans on Drosophila genome have confirmed the antiadipogenic function of $\mathrm{HH}$ signaling. Specifically, $\mathrm{HH}$ signaling blocked differentiation of white adipocytes. Likewise, transgenic activation of $\mathrm{HH}$ signaling in both
Drosophila and mammalian models impaired fat formation $[140,141]$. Using multipotent C3H10T1/2 cells, treatment with SHH resulted in the suppression of the proadipogenic effects of bone morphogenetic protein (BMP)2 [142].

In addition to its antiadipogenic properties, $\mathrm{HH}$ signaling is well known to stimulate MSC osteogenic differentiation. While the exact mechanism and stage at which $\mathrm{HH}$ acts during osteoblastogenesis are not completely understood, both in vivo and in vitro data suggest that bone formation occurs via a positive feedback loop. That is, $\mathrm{HH}$-induced osteoblastogenesis requires BMP signaling, and together they elicit a synergistic expression of alkaline phosphatase activity [143]. This positive feedback loop is further mediated by Gli2 transcription, which serves to upregulate BMP-2 expression, which in turn activates Gli transcription [144]. In the murine MSC line $\mathrm{C} 3 \mathrm{H} 10 \mathrm{~T} 1 / 2, \mathrm{HH}$ simultaneously induced osteoblastic differentiation while inhibiting adipogenesis [145-147]. In KS483 cells, a similar induction of osteogenesis via $\mathrm{SHH}$ was observed alongside inhibited adipogenesis, despite adipogenic culture conditions [148]. It is important to note that SHH induced differentiation was only observed in immature mesenchymal cell lines 3H10T1/2 and not pre-osteoblastic MC3T3-E1 or osteoblastic cell lines OS 17/2.8 and ROB-C26 $[143,147]$. These data imply that SHH activity may be key in stimulating osteoblastogenesis only during early stages of cell differentiation. In summary, current data suggest that $\mathrm{HH}$ signaling promotes MSC osteogenic differentiation over adipogenic differentiation, primarily via Gli transcriptional factor activity.

\section{Control of Adipogenesis and Osteogenesis by NELL-1 Signaling}

The secreted molecule NELL-1 (NEL-like protein 1) was first discovered to have osteoinductive properties by its 


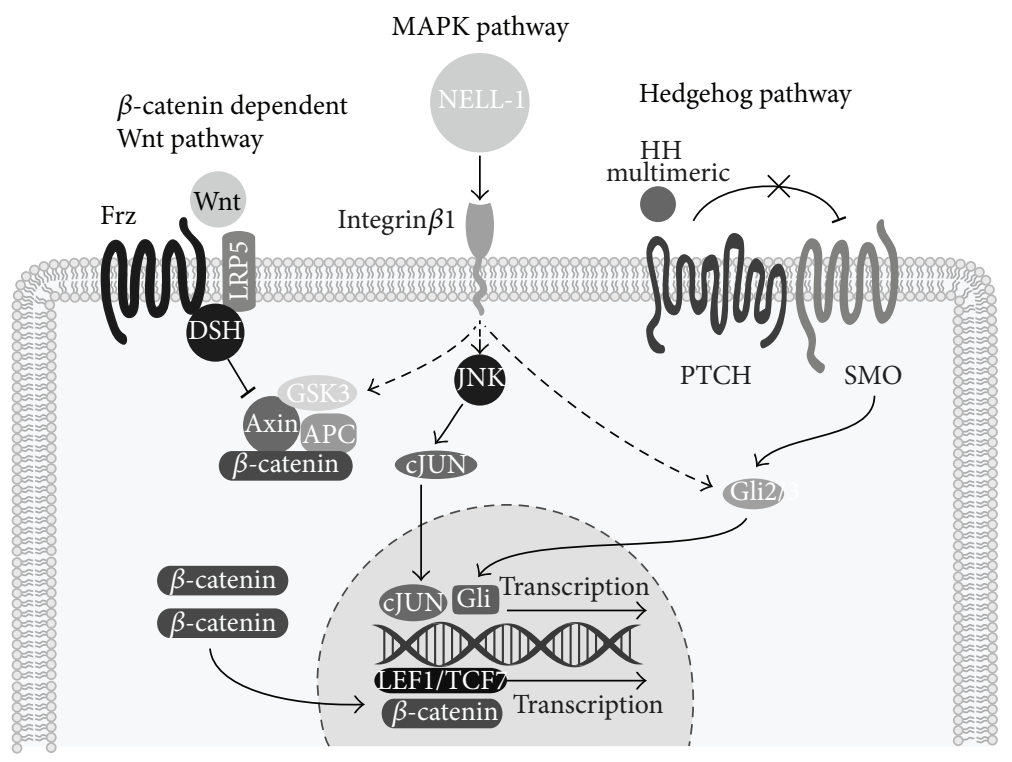

FIGURE 5: Schematic of NELL-1 signaling pathway. NELL-1 is a secreted osteoinductive protein that binds to the cell surface receptor Integrin $\beta 1$. Binding to Integrin $\alpha 3$ has also been reported. Multiple intracellular signaling pathways have been shown to increase after NELL-1 stimulation, including MAPK, Hedgehog, and $\beta$-catenin dependent Wnt signaling. Although the relative importance of these pathways is still undefined, NELL-1 treatment results in increased Runx 2 transcription, Runx2 phosphorylation, and induction of osteogenic programming.

overexpression during premature bone formation in human sporadic coronal craniosynostosis [149, 150]. NELL-1 is expressed during both intramembranous and endochondral bone formation. Overexpression increases both differentiation and mineralization selectively in osteoblasts and is highly specific to the osteochondral lineage [151]. Transgenic mice overexpressing NELL-1 show premature cranial suture fusion and bone overgrowth, thus replicating the human observed phenotype [152]. Interestingly, the nontissue specific overexpression of NELL-1 in mice only manifested phenotypes in the calvarial bone. This finding suggests a relative osteospecific effect of NELL-1 signaling. Conversely, downregulation of NELL-1 resulted in inhibited osteoblastogenesis in vitro in primary cultures of fetal rat calvarial cells and MC3T3 cell line cultures [152]. Moreover, complete loss of NELL-1 in mice results in significant reduction in the mineralization of calvarial bones and attenuated osteoblastogenesis [153]. Thus, NELL-1 has been shown to have a critical role in craniofacial osteogenic differentiation and bone formation [152].

The osteoblastogenic effects of NELL-1 have been studied in the context of bone tissue engineering. For example, in vivo NELL-1 administration induces significant calvarial defect healing in rats [154]. When NELL-1 was applied to a PLGA scaffold in a rat calvarial defect, decreased Osterix-producing cells were observed, concomitantly with increased bone sialoprotein, osteocalcin, and BMP-7 [149]. In vivo, several studies have demonstrated that NELL-1 has comparable bone regeneration capacity as BMP-2, in both calvarial defect and spinal fusion models, among others [149, 155]. NELL-1 has also been applied to critical-sized femoral segment defect models in rats, observing to enhanced bone regeneration/osseous union [156]. A variety of spinal fusion models have also been investigated across several animal models. For example, NELL-1 demonstrated osteoinductive properties in rat spinal fusions $[154,157]$, using apatite coated alginate/chitosan microparticles and $\beta$-TCP scaffolds [158]. In a sheep spinal fusion model using demineralized bone graft, NELL-1 increased both bone volume and mineral density at three months, with a similar bone-forming efficacy to BMP-2 [155]. Overall, NELL-1 demonstrates robust induction of bone throughout many in vivo models, ranging from rodents to large preclinical animals [151].

Mechanistically, NELL-1 is directly regulated by the transcription factor Runx2 [74, 151, 154]. NELL-1 is preferentially expressed in osteoblasts in levels similar to Runx2 and is most highly expressed during skeletogenesis [74, 151]. In Runx2 deficient mice, overexpression of NELL-1 was not sufficient to rescue mineralization, whereas absence of NELL-1 significantly decreased Runx2 activity in vitro [74]. Integrin $\beta 1$ was recently identified as the first cell surface receptor of NELL-1 [159]. Cell surface binding in a preosteoblast cell line required Integrin $\beta 1$ expression [159]. Moreover, siRNA for Integrin $\beta 1$ blocked at least some of the cellular effects of NELL-1, including induction of preosteoblast attachment [159]. NELL-1 is known to promote osteogenesis accompanied by activation of MAPK, canonical Wnt and HH signaling [41, 42, 160, 161] (Figure 5). NELL-1 activates both ERK1/2 and JNK1 MAPK pathways in Saos2 osteosarcoma cell type [160]. This activation of MAPK signaling is associated with Runx2 protein phosphorylation (activation) [160]. In addition, NELL-1 induced MAPK activity is accompanied by activation of phosphate transporters Pitl and Pit2 to increase pre-osteoblast mineralization [162]. NELL-1 induction of Wnt signaling has been observed in both osteoblastic and osteoclastic cell types and is associated with its proosteogenic and antiosteoclastic effects [161]. The 
activation of $\mathrm{HH}$ signaling by NELL-1 has thus far been observed in preadipocytes only [42].

Recent data has shown that NELL-1 also exerts antiadipogenic effects [41]. These effects were found both in the preadipocyte cell line 3T3-L1 cells, as well as primary adiposederived MSC (ASC) [41]. This was observed both in adipocyte specific gene expression and intracellular lipid accumulation. Recent in vivo studies have confirmed the antiadipogenic effects of NELL-1, in which direct intramedullary injection of NELL-1 reduced intramarrow adipocytes in a senile rat model [163]. This antiadipogenic effects of NELL-1 in preadipocytes is associated with activation of $\mathrm{HH}$ signaling, including $\mathrm{HH}$ signaling markers Ihh, Glil, and Ptcl. Further studies found that coapplication of NELL-1 with cyclopamine, an antagonist for Smoothened, completely reversed or blunted the proosteogenic effects of NELL-1 [42]. Thus, NELL-1 is an osteoinductive cytokine with concomitant antiadipogenic properties. These effects may be through activation/intersection with MAPK, Wnt, and $\mathrm{HH}$ signaling.

\section{Control of Adipogenesis and Osteogenesis by BMP Signaling}

Bone morphogenetic proteins (BMPs), members of transforming growth factor- $\beta$ (TGF- $\beta$ ) superfamily, are extracellular cytokines originally isolated from bone extract and found to induce of ectopic chondrogenesis and osteogenesis [164]. BMPs are responsible for numerous cell regulatory processes, including the differentiation and patterning of bone and cartilage [165]. Over 20 different BMPs have been identified, of which BMP-2, $-4,-7,-9$, and -13 are most commonly studied in the context of MSC differentiation $[45,166]$. Both recombinant BMP-2 and -7 are approved by the FDA for the regeneration of bone in spinal fusion surgery and commonly used off-label for other orthopaedic applications $[167,168]$.

BMPs produce their effects through interaction with two serine-threonine kinase cell surface BMP receptors (BMPRs). Type II BMPRs initiate signaling upon binding to a BMP ligand, following which recruitment, phosphorylation, and activation of type I BMPRs occurs $[165,169,170]$. While there are several different type I BMPRs, only a few are involved in MSC differentiation, including BMPR-IA and BMPR-IB [47]. Several downstream BMP signaling elements exist, including Smad1/5/8, MAP Kinase, and c-Jun N-terminal kinase (JNK) signaling pathways, which are phosphorylated and thereby activated $[47,84,171]$. Of these, Smad1/5/8 signaling transduction is the most pertinent to MSC differentiation, as it is principally through the Smad-protein complexes that transcriptional regulation of adipogenic and osteogenic programming is regulated $[165,169,170]$ (see [172] for a more detailed review of BMP signaling transduction).

BMP induced adipogenesis involves both $S m a d 1 / 5 / 8$ and MAPK activation [173]. BMP induced Smad1/5/8 signaling activates PPAR $\gamma$ via zinc finger transcription factor Schnurri2 and $\mathrm{C} / \mathrm{EBP} \alpha$, which exhibit synergistic, adipogenic effects $[33,174]$. Accordingly, a Smad antagonist such as Smad6 reduces both PPAR $\gamma$ signaling and BMP-associated adipogenesis [173]. Similar to Smad1/5/8 signaling, BMP induced activation of MAPK signaling is associated with PPAR $\gamma$ activation and adipogenic differentiation [173]. Conversely, disruption of MAPK signaling also inhibits both PPAR $\gamma$ expression and BMP-associated adipogenesis [173]. Investigators have identified BMP signaling activity at the earliest stages of MSC adipogenesis [175, 176]. When MSC are forced into a preadipocyte cell lineage via exposure to 5azacytidine, a potent inhibitor of DNA methylation, BMP4 expression increases $[175,176]$. BMP-4 has also been shown to have significance in brown adipose tissue, which prioritizes heat production over energy storage [177, 178]. Forced expression of BMP-4 in white adipocytes induces a brown adipocyte phenotype, including increased energy expenditure and insulin sensitivity [179]. Moreover, once MSC have been forced into preadipocyte cells, BMP-4 overexpression is sufficient to induce commitment to adipocyte lineage differentiation $[45,175,180]$.

BMP signaling is one of the central signaling pathways involved in the induction of osteogenic differentiation and regulation of bone formation. Multiple murine studies involving genetically modified BMP ligands, BMP receptors, and BMP inhibitors demonstrate a critical role for BMP signaling in bone formation [181-184]. For example, transgenic mice with modified BMPR-IA receptors exhibit low bone mass and irregular calcification [181]. Inhibitors of BMP signaling, such as Noggin and Gremlin, impair bone formation when overexpressed $[179,185,186]$. In general, BMP induced osteogenesis utilizes both autocrine and paracrine pathways $[187,188]$ and works in conjunction with Osterix via both Runx2 dependent and independent pathways. BMP receptor activation in osteogenesis, as in adipogenesis, involves both Smad1/5/8 and MAPK downstream signaling activation. While 31 different BMP ligands are identified to date, only several actually promote MSC osteogenic differentiation [189]. Specifically, BMP-2, -4, -6, 7 , and -9 have been shown to promote osteogenic commitment, as well as terminal osteogenic differentiation in MSC $[45,46]$. BMP-2, the most commonly studied BMP ligand, induces MSC osteogenesis both in vitro and in vivo [190-197]. Furthermore, investigators have found that short-term BMP2 treatment is both necessary and sufficient for osteogenic commitment in the C3H10T1/2 cell line [198]. It is important to note that murine-derived MSC in general show a robust osteogenic response to BMP signaling, whereas human MSC show a more variable response. For example, several studies evaluating BMP-2, -4 , or -7 in human MSC did not observe reliably increased osteogenic differentiation [199]. Further investigation has suggested that higher expression of the BMP antagonist Noggin may underlie the variable response of human MSC to BMP-induced osteogenesis [200, 201].

The precise determinants that govern BMP signaling induced adipogenesis versus osteogenesis in MSC are not well understood. Two variables that may determine the effects of BMP on MSC differentiation have been observed: dosage and receptor type. In terms of dosage, lower concentrations of BMP-2 have been shown to directs towards adipocyte formation, while higher concentrations favor osteogenic differentiation in C3H10T1/2 [48]. However, these effects of dosage may be ligand- and cell-type dependent. In terms of 
receptor type, signaling through BMPR-IA in general induces adipogenic effects, while signaling via BMPR-1B induces osteogenic effects. For example, expression of constitutively active BMPR-IA induces adipogenic differentiation, while overexpression of inactive BMPR-IA inhibits adipogenic differentiation [47]. The converse effects were obtained by manipulation of BMPR-IB expression. Namely, constitutive BMPR-IB activation induces osteogenic differentiation while inactive BMPR-IB inhibited osteogenic differentiation [47]. However, conflicting data does exist regarding the specificity of BMPRs for lineage differentiation. For example, osteoblast-selective interference of BMPR-IA demonstrated anti-osteogenic effects including irregular calcification and decreased bone mass [181]. Thus, BMP receptor type and dosage are two known variables that have effect on MSC lineage determination, although no global rule applies [202].

\section{Control of Adipogenesis and Osteogenesis by IGF Signaling}

Discovered over fifty years ago, insulin-like growth factorI (IGF-I) was originally identified as a soluble factor with insulin-like properties and induced by a growth hormone. Since then, we have developed a better understanding of this cytokine, especially in regard to its contribution towards bone formation and remodeling $[203,204]$ and adipogenesis. As a peptide hormone that acts in an endocrine, paracrine, and autocrine manner [205], IGF-1 primarily elicits effects via the IGF-I receptor (IGF1R) and IGF-binding proteins (IGFBPs) 1-6 [206]. While IGF-1 is primarily concentrated in the liver, it can be found systemically and is present in most peripheral tissues, including bone $[204,206,207]$. The functions of IGF1 in bone have been well documented.

IGF-1 produces its effect by inducing several intracellular signaling pathways. IGF-1 first binds to the IGF-1 receptor, which autophosphorylates the receptor intracellularly at the kinase domain. With the receptor now activated, various protein substrates are consequently activated, including insulin receptor substrate-1 (IRS-1) and Src homology and collagen protein (SHC) [206]. IRS-1 goes on to activate the phosphoinositol 3-kinase (PI3-K), 3-PI-dependent kinase- (PDK-1), and Akt pathways, while SHC is responsible for activating the Ras/Raf/mitogen-activated protein (MAP) kinase pathways [207]. IRS-1 elicits its effect through interaction with and activation of PI3K, thereby catalyzing the phosphorylation of PIP2 to PIP3. The elevated levels of PIP3 consequently activate PDK-1 and Akt [208]. Activation of PI3K, PDK-1, and Akt has been shown to be important in skeletal growth [208, 209]. In fact, knockout Akt1/Akt2 mice demonstrate significantly impaired bone development and skeletal growth [208]. Meanwhile, SHC, which forms a complex with Grb2 and SOC, is responsible for increasing cell proliferation through activation of the Ras/Raf-1/MAPK pathway [206].

During bone remodeling, IGF-1 is released from the bone matrix to stimulate MSC osteoblastogenesis via activation of mammalian target of rapamycin (mTOR). This allows for the maintenance of both bone structure and mass, both of which were downregulated in mice with knockout of IGF1 receptors in pre-osteoblastic cells [210]. Similarly, mice with deleted IGF-1 receptors in osteoclasts exhibit increased bone formation from decreased osteoclast formation [211]. Interestingly, IGF binding protein 3 is also a corequisite for IGF-1 in the bone matrix to stimulate new bone formation in rats [210]. Interestingly, while IGF binding protein 5 has exhibited proosteogenic properties in several studies, it also demonstrates inhibition of bone formation through impairing IGF-induced osteoblastogenesis [212]. Additionally, in serum-deprived conditions, MSC were shown to proliferate in response to IGF-1 [213]. Upstream, serum response factor (SRF) is found to regulate both IGF-1 and Runx2 signaling to control bone formation. In mice with conditional deletion of SRF in osteoblasts, Runx 2 transactivity was restored via overexpression of SRF. SRF then plays an important role for IGF1-induced osteoblastogenesis and mineralization through regulation of IGF-1 expression and Runx2 transactivity [214]. Collectively, these studies confirm the importance of IGF1 , its receptor, and respective binding protein for osteogenic differentiation and bone remodeling.

Combination of IGF-1 with various other growth factors provides additional insight on the mechanism of bone formation by IGF-1. For example, the addition of PDGF with IGF has been demonstrated to be more efficacious than either alone in terms of osteogenic induction in ASC [215]. Likewise, the combination of IGF-1 with AMD3100, an antagonist of chemokine receptor of CxCR4, showed significant augmentation of bone growth in segmental fracture murine models, associated with facilitation by the Akt/PI3K, MEK1/2-Erk1/2, and Smad2/3 signaling pathways [216]. In a distraction osteogenesis sheep model, application of both IGF-1 and TGF- $\beta 1$ led to accelerated bone healing [217]. Another study found that growth hormone (GH) could increase to compensate for IGF-1 deficiency in mice to protect against inhibition of bone modeling during growth [218]. PTH is also known to stimulate both osteoblast and osteoclast function [211], with a role in modulating IGF-1 signaling through mechanisms involving IHH and ephrins [219]. Furthermore, there is a potential crosstalk between IGF-1 signaling and the integrin mechanosensing pathways, as evidenced by the failure of skeletal unloading to aid in bone growth despite IGF-1 infusion [219].

Interestingly, IGF-1 has been found to promote both adipogenic and osteogenic differentiation. For example, IGF1 induces cell division of adipocyte precursor cells [220]. In addition, IGF receptors are involved in promoting adipogenesis through induction of advanced glycation end products (AGEs). AGEs activate both $\mathrm{NAD}(\mathrm{P}) \mathrm{H}$ oxidase and Src, which ultimately leads to the phosphorylation/activation of both IGF-1 receptor and Akt downstream in 3T3-L1 preadipocyte cells [221]. Further, Akt1/Akt2 knockout mice demonstrate impaired adipogenesis [208]. In fact, it has been shown that both Akt1 and Akt2 are necessary to induce $\operatorname{PPAR} \gamma$, the key regulator for adipogenesis. Thus, a critical threshold of Akt activity, as regulated by IGF-1, contributes to the maintenance of cell proliferation, growth, and adipogenic differentiation [208]. 


\section{Discussion}

Numerous signaling pathways induce the adipogenic and/or osteogenic differentiation of MSC, not all of which were covered in this review. The majority of signaling pathways ultimately converge downstream affecting PPAR $\gamma$ or Runx2 expression, transcriptional activity, or both. Although the mechanisms have not been fully discerned, many of these growth factors tend to elicit an "inverse relationship" between adipogenic and osteogenic differentiation. As discussed, Wnt, HH, and NELL-1 signaling follow this pattern, exhibiting proosteogenic/antiadipogenic effects [222]. Other well-studied signaling pathways further support this inverse relationship, including fibroblast growth factor-2 (FGF-2) [223], TGF- $\beta 1[69,224]$, and Notch signaling pathway [225], to name a few. Likewise, other transcription factors besides Runx 2 demonstrate a proosteogenic, antiadipocytic relationship, one example being the recently described transcriptional activator TAZ (transcriptional activator with PDZ binding motif) [226]. However, there are a few exceptions to this pattern. For example, both IGF and BMP signaling have pleotropic, proosteogenic and proadipocytic properties [198, 227-229]. In summary, an inverse relationship exists between adipogenic and osteogenic lineage differentiation in MSC governed by diverse signaling pathways. The understanding of this relationship has far-reaching implications for the understanding of human health and treatment of human disease.

\section{Conflict of Interests}

The author declares no conflict of interests.

\section{Acknowledgment}

The author would like to thank A. Nguyen for his excellent technical assistance.

\section{References}

[1] W. M. Jackson, L. J. Nesti, and R. S. Tuan, "Concise review: clinical translation of wound healing therapies based on mesenchymal stem cells," Stem Cells Translational Medicine, vol. 1, no. 1, pp. 44-50, 2012.

[2] G. Chamberlain, J. Fox, B. Ashton, and J. Middleton, "Concise review: mesenchymal stem cells: their phenotype, differentiation capacity, immunological features, and potential for homing," Stem Cells, vol. 25, no. 11, pp. 2739-2749, 2007.

[3] B. Levi and M. T. Longaker, "Concise review: adipose-derived stromal cells for skeletal regenerative medicine," Stem Cells, vol. 29, no. 4, pp. 576-582, 2011.

[4] H. Mizuno, M. Tobita, and A. C. Uysal, "Concise review: adipose-derived stem cells as a novel tool for future regenerative medicine," Stem Cells, vol. 30, no. 5, pp. 804-810, 2012.

[5] A. W. James, J. N. Zara, X. Zhang et al., "Perivascular stem cells: a prospectively purified mesenchymal stem cell population for bone tissue engineering," Stem Cells Translational Medicine, vol. 1, no. 6, pp. 510-519, 2012.
[6] B. Levi, A. W. James, E. R. Nelson et al., "Human adipose derived stromal cells heal critical size mouse calvarial defects," PLoS ONE, vol. 5, no. 6, Article ID e11177, 2010.

[7] B. Levi, D. C. Wan, J. P. Glotzbach et al., "CD105 protein depletion enhances human adipose-derived stromal cell osteogenesis through reduction of transforming growth factor $\beta 1$ (TGF- $\beta 1$ ) signaling," The Journal of Biological Chemistry, vol. 286, no. 45, pp. 39497-39509, 2011.

[8] D. W. Kim, M. Staples, K. Shinozuka et al., "Wharton's Jellyderived mesenchymal stem cells: phenotypic characterization and optimizing their therapeutic potential for clinical applications," International Journal of Molecular Sciences, vol. 14, no. 6, pp. 11692-11712, 2013.

[9] S. Corrao, G. la Rocca, M. Lo Iacono, T. Corsello, F. Farina, and R. Anzalone, "Umbilical cord revisited: from Wharton's jelly myofibroblasts to mesenchymal stem cells," Histology and Histopathology, vol. 28, no. 10, pp. 1235-1244, 2013.

[10] M. Corselli, M. Crisan, I. R. Murray et al., "Identification of perivascular mesenchymal stromal/stem cells by flow cytometry," Cytometry A, vol. 83, no. 8, pp. 714-720, 2013.

[11] A. W. James, J. N. Zarab, M. Corselli et al., "An abundant perivascular source of stem cells for bone tissue engineering," Stem Cells Translational Medicine, vol. 1, no. 9, pp. 673-684, 2012.

[12] M. Corselli, C. W. Chen, B. Sun et al., "The tunica adventitia of human arteries and veins as a source of mesenchymal stem cells," Stem Cells and Development, vol. 21, no. 8, pp. 1299-1308, 2012.

[13] M. Crisan, S. Yap, L. Casteilla et al., "A perivascular origin for mesenchymal stem cells in multiple human organs," Cell Stem Cell, vol. 3, no. 3, pp. 301-313, 2008.

[14] J. Sammons, N. Ahmed, M. El-Sheemy, and H. T. Hassan, "The role of BMP-6, IL-6, and BMP-4 in mesenchymal stem celldependent bone development: effects on osteoblastic differentiation induced by parathyroid hormone and vitamin D3," Stem Cells and Development, vol. 13, no. 3, pp. 273-280, 2004.

[15] A. Augello and C. De Bari, "The regulation of differentiation in mesenchymal stem cells," Human Gene Therapy, vol. 21, no. 10, pp. 1226-1238, 2010.

[16] D. J. Kelly and C. R. Jacobs, “The role of mechanical signals in regulating chondrogenesis and osteogenesis of mesenchymal stem cells," Birth Defects Research C, vol. 90, no. 1, pp. 75-85, 2010.

[17] M. Hronik-Tupaj, W. L. Rice, M. Cronin-Golomb, D. L. Kaplan, and I. Georgakoudi, "Osteoblastic differentiation and stress response of human mesenchymal stem cells exposed to alternating current electric fields," BioMedical Engineering Online, vol. 10, article 9, 2011.

[18] C. M. Creecy, C. F. O’Neill, B. P. Arulanandam, V. L. Sylvia, C. S. Navara, and R. Bizios, "Mesenchymal stem cell osteodifferentiation in response to alternating electric current," Tissue Engineering A, vol. 19, no. 3-4, pp. 467-474.

[19] K. E. Hammerick, A. W. James, Z. Huang, F. B. Prinz, and M. T. Longaker, "Pulsed direct current electric fields enhance osteogenesis in adipose-derived stromal cells," Tissue Engineering A, vol. 16, no. 3, pp. 917-931, 2010.

[20] J. Yan, L. Dong, B. Zhang, and N. Qi, "Effects of extremely low-frequency magnetic field on growth and differentiation of human mesenchymal stem cells," Electromagnetic Biology and Medicine, vol. 29, no. 4, pp. 165-176, 2010.

[21] S. Muruganandan, A. A. Roman, and C. J. Sinal, "Adipocyte differentiation of bone marrow-derived mesenchymal stem 
cells: cross talk with the osteoblastogenic program," Cellular and Molecular Life Sciences, vol. 66, no. 2, pp. 236-253, 2009.

[22] E. D. Rosen and O. A. MacDougald, "Adipocyte differentiation from the inside out," Nature Reviews Molecular Cell Biology, vol. 7, no. 12, pp. 885-896, 2006.

[23] E. D. Rosen, C. J. Walkey, P. Puigserver, and B. M. Spiegelman, "Transcriptional regulation of adipogenesis," Genes and Development, vol. 14, no. 11, pp. 1293-1307, 2000.

[24] R. Berry and M. S. Rodeheffer, "Characterization of the adipocyte cellular lineage in vivo," Nature Cell Biology, vol. 15, no. 3, pp. 302-308.

[25] M. Jumabay, R. Abdmaulen, S. Urs et al., "Endothelial differentiation in multipotent cells derived from mouse and human white mature adipocytes," Journal of Molecular and Cellular Cardiology, vol. 53, no. 6, pp. 790-800, 2012.

[26] I. O. Vroegrijk, J. B. van Klinken, J. A. van Diepen et al., "Cd36 is important for adipocyte recruitment and affects lipolysis," Obesity, 2013.

[27] A. Neve, A. Corrado, and F. P. Cantatore, "Osteoblast physiology in normal and pathological conditions," Cell and Tissue Research, vol. 343, no. 2, pp. 289-302, 2011.

[28] K. Watanabe and K. Ikeda, "Osteoblast differentiation and bone formation," Nippon Rinsho, vol. 67, no. 5, pp. 879-886, 2009.

[29] A. W. James, S. Pang, A. Askarinam, M. Corselli et al., "Additive effects of sonic hedgehog and Nell-1 signaling in osteogenic versus adipogenic differentiation of human adipose-derived stromal cells," Stem Cells and Development, vol. 21, no. 12, pp. 2170-2178.

[30] L. Pei and P. Tontonoz, "Fat's loss is bone's gain," Journal of Clinical Investigation, vol. 113, no. 6, pp. 805-806, 2004.

[31] J. N. Beresford, J. H. Bennett, C. Devlin, P. S. Leboy, and M. E. Owen, "Evidence for an inverse relationship between the differentiation of adipocytic and osteogenic cells in rat marrow stromal cell cultures," Journal of Cell Science, vol. 102, no. 2, pp. 341-351, 1992.

[32] M.-A. Dorheim, M. Sullivan, V. Dandapani et al., "Osteoblastic gene expression during adipogenesis in hematopoietic supporting murine bone marrow stromal cells," Journal of Cellular Physiology, vol. 154, no. 2, pp. 317-328, 1993.

[33] V. Krishnan, H. U. Bryant, and O. A. MacDougald, "Regulation of bone mass by Wnt signaling," Journal of Clinical Investigation, vol. 116, no. 5, pp. 1202-1209, 2006.

[34] C. N. Bennett, K. A. Longo, W. S. Wright et al., "Regulation of osteoblastogenesis and bone mass by Wnt10b," Proceedings of the National Academy of Sciences of the United States of America, vol. 102, no. 9, pp. 3324-3329, 2005.

[35] Q.-Q. Tang, T. C. Otto, and M. D. Lane, "Commitment of C3H10T1/2 pluripotent stem cells to the adipocyte lineage," Proceedings of the National Academy of Sciences of the United States of America, vol. 101, no. 26, pp. 9607-9611, 2004.

[36] J. Burroughs, P. Gupta, B. R. Blazar, and C. M. Verfaillie, "Diffusible factors from the murine cell line M2-10B4 support human in vitro hematopoiesis," Experimental Hematology, vol. 22, no. 11, pp. 1095-1101, 1994.

[37] I. D’Alimonte, A. Lannutti, C. Pipino et al., "Wnt signaling behaves as a "master regulator" in the osteogenic and adipogenic commitment of human amniotic fluid mesenchymal stem cells," Stem Cell Reviews and Reports, vol. 9, no. 5, pp. 642654, 2013.
[38] H. Taipaleenmäki, B. M. Abdallah, A. AlDahmash, A.-M. Säämänen, and M. Kassem, "Wnt signalling mediates the crosstalk between bone marrow derived pre-adipocytic and preosteoblastic cell populations," Experimental Cell Research, vol. 317, no. 6, pp. 745-756, 2011.

[39] A. W. James, P. Leucht, B. Levi et al., "Sonic hedgehog influences the balance of osteogenesis and adipogenesis in mouse adiposederived stromal cells," Tissue Engineering A, vol. 16, no. 8, pp. 2605-2616, 2010.

[40] C. Fontaine, W. Cousin, M. Plaisant, C. Dani, and P. Peraldi, "Hedgehog signaling alters adipocyte maturation of human mesenchymal stem cells," Stem Cells, vol. 26, no. 4, pp. 10371046, 2008.

[41] A. W. James, A. Pan, M. Chiang et al., "A new function of Nell1 protein in repressing adipogenic differentiation," Biochemical and Biophysical Research Communications, vol. 411, no. 1, pp. 126-131, 2011.

[42] A. W. James, S. Pang, A. Askarinam et al., "Additive effects of sonic hedgehog and Nell-1 signaling in osteogenic versus adipogenic differentiation of human adipose-derived stromal cells," Stem Cells and Development, vol. 21, no. 12, pp. 2170-2178, 2012.

[43] R. E. Jung, S. I. Windisch, A. M. Eggenschwiler, D. S. Thoma, F. E. Weber, and C. H. F. Hämmerle, "A randomized-controlled clinical trial evaluating clinical and radiological outcomes after 3 and 5 years of dental implants placed in bone regenerated by means of GBR techniques with or without the addition of BMP2," Clinical Oral Implants Research, vol. 20, no. 7, pp. 660-666, 2009.

[44] P. C. Bessa, M. Casal, and R. L. Reis, "Bone morphogenetic proteins in tissue engineering: the road from laboratory to clinic, part II (BMP delivery)," Journal of Tissue Engineering and Regenerative Medicine, vol. 2, no. 2-3, pp. 81-96, 2008.

[45] Q. Kang, W.-X. Song, Q. Luo et al., "A Comprehensive analysis of the dual roles of BMPs in regulating adipogenic and osteogenic differentiation of mesenchymal progenitor cells," Stem Cells and Development, vol. 18, no. 4, pp. 545-558, 2009.

[46] L. J. Dorman, M. Tucci, and H. Benghuzzi, "In vitro effects of bmp-2, bmp-, and bmp-13 on proliferation and differentation of mouse mesenchymal stem cells," Biomedical Sciences Instrumentation, vol. 48, pp. 81-87, 2012.

[47] D. Chen, X. Ji, M. A. Harris et al., "Differential roles for bone morphogenetic protein (BMP) receptor type IB and IA in differentiation and specification of mesenchymal precursor cells to osteoblast and adipocyte lineages," Journal of Cell Biology, vol. 142, no. 1, pp. 295-305, 1998.

[48] E. A. Wang, D. I. Israel, S. Kelly, and D. P. Luxenberg, "Bone morphogenetic protein-2 causes commitment and differentiation in C3H10T1/2 and 3T3 cells," Growth Factors, vol. 9, no. 1, pp. 57-71, 1993.

[49] M. T. Valenti, U. Garbin, A. Pasini et al., "Role of Ox-PAPCs in the differentiation of mesenchymal stem cells (MSCs) and Runx2 and PPAR $\gamma 2$ expression in MSCs-like of osteoporotic patients," PLoS ONE, vol. 6, no. 6, Article ID e20363, 2011.

[50] L. Zhang, P. Su, C. Xu et al., "Melatonin inhibits adipogenesis and enhances osteogenesis of human mesenchymal stem cells by suppressing PPAR $\gamma$ expression and enhancing Runx 2 expression," Journal of Pineal Research, vol. 49, no. 4, pp. 364-372, 2010.

[51] X. Li, Q. Cui, C. Kao, G.-J. Wang, and G. Balian, "Lovastatin inhibits adipogenic and stimulates osteogenic differentiation by suppressing PPAR $\gamma 2$ and increasing Cbfa1/Runx2 expression in 
bone marrow mesenchymal cell cultures," Bone, vol. 33, no. 4 , pp. 652-659, 2003.

[52] X. Zhang, M. Yang, L. Lin et al., "Runx2 overexpression enhances osteoblastic differentiation and mineralization in adipose-derived stem cells in vitro and in vivo," Calcified Tissue International, vol. 79, no. 3, pp. 169-178, 2006.

[53] X. Zhou, Z. Zhang, J. Q. Feng et al., "Multiple functions of Osterix are required for bone growth and homeostasis in postnatal mice," Proceedings of the National Academy of Sciences of the United States of America, vol. 107, no. 29, pp. 12919-12924, 2010.

[54] G. J. Darlington, S. E. Ross, and O. A. MacDougald, "The role of C/EBP genes in adipocyte differentiation," The Journal of Biological Chemistry, vol. 273, no. 46, pp. 30057-30060, 1998.

[55] S. Wang, Q. Wang, B. E. Crute, I. N. Melnikova, S. R. Keller, and N. A. Speck, "Cloning and characterization of subunits of the Tcell receptor and murine leukemia virus enhancer core-binding factor," Molecular and Cellular Biology, vol. 13, no. 6, pp. 33243339, 1993.

[56] S.-C. Bae, "Regulation mechanisms for the heterodimeric transcription factor, PEBP2/CBF," Histology and Histopathology, vol. 14, no. 4, pp. 1213-1221, 1999.

[57] E. Ogawa, M. Inuzuka, M. Maruyama et al., "Molecular cloning and characterization of PEBP $2 \beta$, the heterodimeric partner of a novel Drosophila runt-related DNA binding protein PEBP $2 \alpha$," Virology, vol. 194, no. 1, pp. 314-331, 1993.

[58] T. E. North, T. Stacy, C. J. Matheny, N. A. Speck, and M. F. T. R. de Bruijn, "Runx1 Is expressed in adult mouse hematopoietic stem cells and differentiating myeloid and lymphoid cells, but not in maturing erythroid cells," Stem Cells, vol. 22, no. 2, pp. 158-168, 2004.

[59] C. A. Yoshida, H. Yamamoto, T. Fujita et al., "Runx2 and Runx3 are essential for chondrocyte maturation, and Runx2 regulates limb growth through induction of Indian hedgehog," Genes and Development, vol. 18, no. 8, pp. 952-963, 2004.

[60] D. Levanon, D. Bettoun, C. Harris-Cerruti et al., "The Runx3 transcription factor regulates development and survival of TrkC dorsal root ganglia neurons," EMBO Journal, vol. 21, no. 13, pp. 3454-3463, 2002.

[61] O. Brenner, D. Levanon, V. Negreanu et al., "Loss of Runx3 function in leukocytes is associated with spontaneously developed colitis and gastric mucosal hyperplasia," Proceedings of the National Academy of Sciences of the United States of America, vol. 101, no. 45, pp. 16016-16021, 2004.

[62] Y. Ito, "RUNX genes in development and cancer: regulation of viral gene expression and the discovery of RUNX family genes," Advances in Cancer Research, vol. 99, pp. 33-76, 2008.

[63] K. Blyth, E. R. Cameron, and J. C. Neil, "The RUNX genes: gain or loss of function in cancer," Nature Reviews Cancer, vol. 5, no. 5, pp. 376-387, 2005.

[64] M. Stewart, A. Terry, M. Hu et al., "Proviral insertions induce the expression of bone-specific isoforms of PEBP $2 \alpha \mathrm{A}$ (CBFA1): evidence for a new myc collaborating oncogene," Proceedings of the National Academy of Sciences of the United States of America, vol. 94, no. 16, pp. 8646-8651, 1997.

[65] A. Goel, C. N. Arnold, P. Tassone et al., "Epigenetic inactivation of RUNX3 in microsatellite unstable sporadic colon cancers," International Journal of Cancer, vol. 112, no. 5, pp. 754-759, 2004.

[66] Q.-L. Li, H.-R. Kim, W.-J. Kim et al., “Transcriptional silencing of the RUNX3 gene by CpG hypermethylation is associated with lung cancer," Biochemical and Biophysical Research Communications, vol. 314, no. 1, pp. 223-228, 2004.
[67] T. Y. Kim, H. J. Lee, K. S. Hwang et al., "Methylation of RUNX3 in various types of human cancers and premalignant stages of gastric carcinoma," Laboratory Investigation, vol. 84, no. 4, pp. 479-484, 2004.

[68] W.-H. Guo, L.-Q. Weng, K. Ito et al., "Inhibition of growth of mouse gastric cancer cells by Runx3, a novel tumor suppressor," Oncogene, vol. 21, no. 54, pp. 8351-8355, 2002.

[69] K.-S. Lee, H.-J. Kim, Q.-L. Li et al., "Runx2 is a common target of transforming growth factor $\beta 1$ and bone morphogenetic protein 2 , and cooperation between Runx 2 and Smad5 induces osteoblast-specific gene expression in the pluripotent mesenchymal precursor cell line C2C12," Molecular and Cellular Biology, vol. 20, no. 23, pp. 8783-8792, 2000.

[70] T. Komori, "Regulation of osteoblast differentiation by runx2," Advances in Experimental Medicine and Biology, vol. 658, pp. 43-49, 2010.

[71] J. Pratap, J. J. Wixted, T. Gaur et al., "Runx2 transcriptional activation of Indian Hedgehog and a downstream bone metastatic pathway in breast cancer cells," Cancer Research, vol. 68, no. 19, pp. 7795-7802, 2008.

[72] F. Otto, A. P. Thornell, T. Crompton et al., "Cbfal, a candidate gene for cleidocranial dysplasia syndrome, is essential for osteoblast differentiation and bone development," Cell, vol. 89, no. 5, pp. 765-771, 1997.

[73] E. Hesse, H. Saito, R. Kiviranta et al., "Zfp521 controls bone mass by HDAC3-dependent attenuation of Runx2 activity," Journal of Cell Biology, vol. 191, no. 7, pp. 1271-1283, 2010.

[74] X. Zhang, K. Ting, C. M. Bessette et al., "Nell-1, a key functional mediator of Runx2, partially rescues calvarial defects in Runx2+/- mice," Journal of Bone and Mineral Research, vol. 26, no. 4, pp. 777-791, 2011.

[75] P. Tontonoz and B. M. Spiegelman, "Fat and beyond: the diverse biology of PPAR $\gamma$," Annual Review of Biochemistry, vol. 77, pp. 289-312, 2008

[76] I. Issemann and S. Green, "Activation of a member of the steroid hormone receptor superfamily by peroxisome proliferators," Nature, vol. 347, no. 6294, pp. 645-650, 1990.

[77] M. Gottlicher, E. Widmark, Q. Li, and J.-A. Gustafsson, "Fatty acids activate a chimera of the clofibric acid-activated receptor and the glucocorticoid receptor," Proceedings of the National Academy of Sciences of the United States of America, vol. 89, no. 10, pp. 4653-4657, 1992.

[78] C. K. Glass, D. W. Rose, and M. G. Rosenfeld, "Nuclear receptor coactivators," Current Opinion in Cell Biology, vol. 9, no. 2, pp. 222-232, 1997.

[79] A. Chawla and M. A. Lazar, "Peroxisome proliferator and retinoid signaling pathways co-regulate preadipocyte phenotype and survival," Proceedings of the National Academy of Sciences of the United States of America, vol. 91, no. 5, pp. 17861790, 1994.

[80] M. Adams, C. T. Montague, J. B. Prins et al., "Activators of peroxisome proliferator-activated receptor $\gamma$ have depotspecific effects on human preadipocyte differentiation," Journal of Clinical Investigation, vol. 100, no. 12, pp. 3149-3153, 1997.

[81] P. Tontonoz, E. Hu, R. A. Graves, A. I. Budavari, and B. M. Spiegelman, "mPPAR $\gamma 2$ : tissue-specific regulator of an adipocyte enhancer," Genes and Development, vol. 8, no. 10, pp. 1224-1234, 1994.

[82] P. Tontonoz, E. Hu, and B. M. Spiegelman, "Stimulation of adipogenesis in fibroblasts by PPAR $\gamma 2$, a lipid-activated transcription factor," Cell, vol. 79, no. 7, pp. 1147-1156, 1994. 
[83] Y. Zhu, C. Qi, J. R. Korenberg et al., "Structural organization of mouse peroxisome proliferator-activated receptor gamma (mPPAR gamma) gene: alternative promoter use and different splicing yield two mPPAR gamma isoforms," Proceedings of the National Academy of Sciences of the United States of America, vol. 92, no. 17, pp. 7921-7925, 1995.

[84] I. Tzameli, H. Fang, M. Ollero et al., "Regulated production of a peroxisome proliferator-activated receptor- $\gamma$ ligand during an early phase of adipocyte differentiation in 3T3-L1 adipocytes," The Journal of Biological Chemistry, vol. 279, no. 34, pp. 3609336102, 2004.

[85] F. J. Schopfer, Y. Lin, P. R. S. Baker et al., "Nitrolinoleic acid: an endogenous peroxisome proliferator-activated receptor $\gamma$ ligand," Proceedings of the National Academy of Sciences of the United States of America, vol. 102, no. 7, pp. 2340-2345, 2005.

[86] J. M. Lehmann, L. B. Moore, T. A. Smith-Oliver, W. O. Wilkison, T. M. Willson, and S. A. Kliewer, "An antidiabetic thiazolidinedione is a high affinity ligand for peroxisome proliferatoractivated receptor $\gamma(\operatorname{PPAR} \gamma)$," The Journal of Biological Chemistry, vol. 270, no. 22, pp. 12953-12956, 1995.

[87] C. J. Walkey and B. M. Spiegelman, "A functional peroxisome proliferator-activated receptor- $\gamma$ ligand-binding domain is not required for adipogenesis," The Journal of Biological Chemistry, vol. 283, no. 36, pp. 24290-24294, 2008.

[88] B. Lecka-Czernik, E. J. Moerman, D. F. Grant, J. M. Lehmann, S. C. Manolagas, and R. L. Jilka, "Divergent effects of selective peroxisome proliferator-activated receptor- $\gamma 2$ ligands on adipocyte versus osteoblast differentiation," Endocrinology, vol. 143, no. 6, pp. 2376-2384, 2002.

[89] O. P. Lazarenko, S. O. Rzonca, L. J. Suva, and B. Lecka-Czernik, "Netoglitazone is a PPAR-gamma ligand with selective effects on bone and fat," Bone, vol. 38, no. 1, pp. 74-84, 2006.

[90] A. A. Ali, R. S. Weinstein, S. A. Stewart, A. M. Parfitt, S. C. Manolagas, and R. L. Jilka, "Rosiglitazone causes bone loss in mice by suppressing osteoblast differentiation and bone formation," Endocrinology, vol. 146, no. 3, pp. 1226-1235, 2005.

[91] S. O. Rzonca, L. J. Suva, D. Gaddy, D. C. Montague, and B. Lecka-Czernik, "Bone is a target for the antidiabetic compound rosiglitazone," Endocrinology, vol. 145, no. 1, pp. 401-406, 2004.

[92] W. Kim, M. Kim, and E. H. Jho, "Wnt/beta-catenin signalling: from plasma membrane to nucleus," Biochemical Journal, vol. 450, no. 1, pp. 9-21, 2013.

[93] C. Niehrs, "The complex world of WNT receptor signalling," Nature Reviews Molecular Cell Biology, vol. 13, no. 12, pp. 767779.

[94] D. C. Berwick and K. Harvey, "The importance of Wnt signalling for neurodegeneration in Parkinson's disease," Biochemical Society Transactions, vol. 40, no. 5, pp. 1123-1128.

[95] B. D. White, A. J. Chien, and D. W. Dawson, "Dysregulation of Wnt/ $\beta$-catenin signaling in gastrointestinal cancers," Gastroenterology, vol. 142, no. 2, pp. 219-232, 2012.

[96] C. P. Xavier, M. Melikova, Y. Chuman et al., "Secreted Frizzledrelated protein potentiation versus inhibition of Wnt3a/betacatenin signaling," Cell Signal, vol. 26, no. 1, pp. 94-101, 2013.

[97] P. Pandur, D. Maurus, and M. Kühl, "Increasingly complex: new players enter the Wnt signaling network," BioEssays, vol. 24, no. 10, pp. 881-884, 2002.

[98] S. L. Etheridge, G. J. Spencer, D. J. Heath, and P. G. Genever, "Expression profiling and functional analysis of Wnt signaling mechanisms in mesenchymal stem cells," Stem Cells, vol. 22, no. 5, pp. 849-860, 2004.
[99] H.-Y. Wang and C. C. Malbon, "Wnt-frizzled signaling to Gprotein-coupled effectors," Cellular and Molecular Life Sciences, vol. 61, no. 1, pp. 69-75, 2004.

[100] F. Li, Z. Z. Chong, and K. Maiese, "Winding through the WNT pathway during cellular development and demise," Histology and Histopathology, vol. 21, no. 1-3, pp. 103-124, 2006.

[101] L. A. Davis and N. I. Zur Nieden, "Mesodermal fate decisions of a stem cell: the Wnt switch," Cellular and Molecular Life Sciences, vol. 65, no. 17, pp. 2658-2674, 2008.

[102] R. van Amerongen, "Alternative Wnt pathways and receptors," Cold Spring Harbor Perspectives in Biology, vol. 4, no. 10, 2012.

[103] N. Case and J. Rubin, " $\beta$-catenin-a supporting role in the skeleton," Journal of Cellular Biochemistry, vol. 110, no. 3, pp. 545-553, 2010.

[104] R. D. Little, J. P. Carulli, R. G. Del Mastro et al., "A mutation in the LDL receptor-related protein 5 gene results in the autosomal dominant high-bone-mass trait," American Journal of Human Genetics, vol. 70, no. 1, pp. 11-19, 2002.

[105] Y. Gong, B. Roger, B. Slee et al., "LDL receptor-related protein 5 (LRP5) affects bone accrual and eye development," Cell, vol. 107, no. 4, pp. 513-523, 2001.

[106] L. M. Boyden, J. Mao, J. Belsky et al., "High bone density due to a mutation in LDL-receptor-related protein 5," The New England Journal of Medicine, vol. 346, no. 20, pp. 1513-1521, 2002.

[107] J. Chen and F. Long, "beta-catenin promotes bone formation and suppresses bone resorption in postnatal growing mice," Journal of Bone and Mineral Research, vol. 28, no. 5, pp. 11601169, 2013.

[108] H. Hu, M. J. Hilton, X. Tu, K. Yu, D. M. Ornitz, and F. Long, "Sequential roles of Hedgehog and Wnt signaling in osteoblast development," Development, vol. 132, no. 1, pp. 49-60, 2005.

[109] T. F. Day, X. Guo, L. Garrett-Beal, and Y. Yang, "Wnt/ $\beta$-catenin signaling in mesenchymal progenitors controls osteoblast and chondrocyte differentiation during vertebrate skeletogenesis," Developmental Cell, vol. 8, no. 5, pp. 739-750, 2005.

[110] T. P. Hill, D. Später, M. M. Taketo, W. Birchmeier, and C. Hartmann, "Canonical Wnt/ $\beta$-catenin signaling prevents osteoblasts from differentiating into chondrocytes," Developmental Cell, vol. 8, no. 5, pp. 727-738, 2005.

[111] S. L. Holmen, C. R. Zylstra, A. Mukherjee et al., "Essential role of $\beta$-catenin in postnatal bone acquisition," The Journal of Biological Chemistry, vol. 280, no. 22, pp. 21162-21168, 2005.

[112] D. A. Glass II, P. Bialek, J. D. Ahn et al., "Canonical Wnt signaling in differentiated osteoblasts controls osteoclast differentiation," Developmental Cell, vol. 8, no. 5, pp. 751-764, 2005.

[113] N. Takahashi, K. Maeda, A. Ishihara, S. Uehara, and Y. Kobayashi, "Regulatory mechanism of osteoclastogenesis by RANKL and Wnt signals," Frontiers in Bioscience, vol. 16, no. 1, pp. 21-30, 2011.

[114] B. Nie, S. Zhou, X. Fang et al., "Implication of receptor activator of NF-kappaB ligand in Wnt/beta-catenin pathway promoting osteoblast-like cell differentiation," Journal of Huazhong University of Science and Technology, vol. 32, no. 6, pp. 818-822, 2012.

[115] D. Gatti, O. Viapiana, E. Fracassi et al., "Sclerostin and DKK1 in postmenopausal osteoporosis treated with denosumab," Journal of Bone and Mineral Research, vol. 27, no. 11, pp. 2259-2263, 2012.

[116] V. Lim and B. L. Clarke, "New therapeutic targets for osteoporosis: beyond denosumab," Maturitas, vol. 73, no. 3, pp. 269-272, 2012. 
[117] D. Padhi, G. Jang, B. Stouch, L. Fang, and E. Posvar, "Singledose, placebo-controlled, randomized study of AMG 785, a sclerostin monoclonal antibody," Journal of Bone and Mineral Research, vol. 26, no. 1, pp. 19-26, 2011.

[118] S. E. Papapoulos, "Targeting sclerostin as potential treatment of osteoporosis," Annals of the Rheumatic Diseases, vol. 70, no. 1, pp. i119-i122, 2011.

[119] M. Laudes, "Role of WNT signalling in the determination of human mesenchymal stem cells into preadipocytes," Journal of Molecular Endocrinology, vol. 46, no. 2, pp. 65-72, 2011.

[120] S. E. Ross, N. Hemati, K. A. Longo et al., "Inhibition of adipogenesis by Wnt signaling," Science, vol. 289, no. 5481, pp. 950-953, 2000.

[121] J. Liu and S. R. Farmer, "Regulating the balance between peroxisome proliferator-activated receptor $\gamma$ and $\beta$-catenin signaling during adipogenesis: a glycogen synthase kinase $3 \beta$ phosphorylation-defective mutant of $\beta$-catenin inhibits expression of a subset of adipogenic genes," The Journal of Biological Chemistry, vol. 279, no. 43, pp. 45020-45027, 2004.

[122] M. Laudes, "Role of WNT signalling in the determination of human mesenchymal stem cells into preadipocytes," Journal of Molecular Endocrinology, vol. 46, no. 2, pp. 65-72, 2011.

[123] M. Moldes, Y. Zuo, R. F. Morrison et al., "Peroxisomeproliferator-activated receptor $\gamma$ suppresses Wnt/ $\beta$-catenin signalling during adipogenesis," Biochemical Journal, vol. 376, no. 3, pp. 607-613, 2003.

[124] C. N. Bennett, S. E. Ross, K. A. Longo et al., "Regulation of Wnt signaling during adipogenesis," The Journal of Biological Chemistry, vol. 277, no. 34, pp. 30998-31004, 2002.

[125] M. Kawai, S. Mushiakea, K. Bessho et al., "Wnt/Lrp/betacatenin signaling suppresses adipogenesis by inhibiting mutual activation of PPARgamma and C/EBPalpha," Biochemical and Biophysical Research Communications, vol. 363, no. 2, pp. 276282, 2007.

[126] H.-X. Li, X. Luo, R.-X. Liu, Y.-J. Yang, and G.-S. Yang, "Roles of $\mathrm{Wnt} / \beta$-catenin signaling in adipogenic differentiation potential of adipose-derived mesenchymal stem cells," Molecular and Cellular Endocrinology, vol. 291, no. 1-2, pp. 116-124, 2008.

[127] C. Galli, M. Piemontese, S. Lumetti et al., "GSK3b-inhibitor lithium chloride enhances activation of Wnt canonical signaling and osteoblast differentiation on hydrophilic titanium surfaces," Clinical Oral Implants Research, vol. 24, no. 8, pp. 921-927, 2013.

[128] C. N. Bennett, H. Ouyang, Y. L. Ma et al., "Wnt10b increases postnatal bone formation by enhancing osteoblast differentiation," Journal of Bone and Mineral Research, vol. 22, no. 12, pp. 1924-1932, 2007.

[129] W. P. Cawthorn, A. J. Bree, Y. Yao et al., "Wnt6, Wnt10a and Wnt10b inhibit adipogenesis and stimulate osteoblastogenesis through a $\beta$-catenin-dependent mechanism," Bone, vol. 50, no. 2, pp. 477-489, 2012.

[130] C. H. M. Castro, C. S. Shin, J. P. Stains et al., “Targeted expression of a dominant-negative $\mathrm{N}$-cadherin in vivo delays peak bone mass and increases adipogenesis," Journal of Cell Science, vol. 117, no. 13, pp. 2853-2864, 2004.

[131] B. Gustafson, B. Eliasson, and U. Smith, “Thiazolidinediones increase the wingless-type MMTV integration site family (WNT) inhibitor Dickkopf-1 in adipocytes: a link with osteogenesis," Diabetologia, vol. 53, no. 3, pp. 536-540, 2010.

[132] I. Takada, M. Mihara, M. Suzawa et al., "A histone lysine methyltransferase activated by non-canonical Wnt signalling suppresses PPAR- $\gamma$ transactivation," Nature Cell Biology, vol. 9, no. 11, pp. 1273-1285, 2007.
[133] H. H.-C. Yao, W. Whoriskey, and B. Capel, "Desert Hedgehog/Patched 1 signaling specifies fetal Leydig cell fate in testis organogenesis," Genes and Development, vol. 16, no. 11, pp. 14331440, 2002.

[134] R. D. Riddle, R. L. Johnson, E. Laufer, and C. Tabin, "Sonic hedgehog mediates the polarizing activity of the ZPA," Cell, vol. 75, no. 7, pp. 1401-1416, 1993.

[135] M. Ruat, H. Roudaut, J. Ferent, and E. Traiffort, "Hedgehog trafficking, cilia and brain functions," Differentiation, vol. 83, no. 2, pp. S97-S104, 2012.

[136] M. J. Bitgood and A. P. McMahon, "Hedgehog and Bmp genes are coexpressed at many diverse sites of cell-cell interaction in the mouse embryo," Developmental Biology, vol. 172, no. 1, pp. 126-138, 1995.

[137] L. Nanni, J. E. Ming, M. Bocian et al., "The mutational spectrum of the Sonic Hedgehog gene in holoprosencephaly: SHH mutations cause a significant proportion of autosomal dominant holoprosencephaly," Human Molecular Genetics, vol. 8, no. 13, pp. 2479-2488, 1999.

[138] F. Simpson, M. C. Kerr, and C. Wicking, “Trafficking, development and hedgehog," Mechanisms of Development, vol. 126, no. 5-6, pp. 279-288, 2009.

[139] S. Sinha and J. K. Chen, "Purmorphamine activates the Hedgehog pathway by targeting Smoothened," Nature Chemical Biology, vol. 2, no. 1, pp. 29-30, 2006.

[140] J. A. Pospisilik, D. Schramek, H. Schnidar et al., "Drosophila genome-wide obesity screen reveals hedgehog as a determinant of brown versus white adipose cell fate," Cell, vol. 140, no. 1, pp. 148-160, 2010.

[141] J. M. Suh, X. Gao, J. McKay, R. McKay, Z. Salo, and J. M. Graff, "Hedgehog signaling plays a conserved role in inhibiting fat formation," Cell Metabolism, vol. 3, no. 1, pp. 25-34, 2006.

[142] B. K. Zehentner, U. Leser, and H. Burtscher, "BMP-2 and sonic hedgehog have contrary effects on adipocyte-like differentiation of C3H10T1/2 cells," DNA and Cell Biology, vol. 19, no. 5, pp. 275281, 2000.

[143] T. Yuasa, H. Kataoka, N. Kinto et al., "Sonic hedgehog is involved in osteoblast differentiation by cooperating with BMP2," Journal of Cellular Physiology, vol. 193, no. 2, pp. 225-232, 2002.

[144] M. Zhao, M. Qiao, S. E. Harris, D. Chen, B. O. Oyajobi, and G. R. Mundy, "The zinc finger transcription factor Gli2 mediates bone morphogenetic protein 2 expression in osteoblasts in response to hedgehog signaling," Molecular and Cellular Biology, vol. 26, no. 16, pp. 6197-6208, 2006.

[145] T. Nakamura, T. Aikawaa, M. Iwamoto-Enomoto et al., "Induction of osteogenic differentiation by hedgehog proteins," Biochemical and Biophysical Research Communications, vol. 237, no. 2, pp. 465-469, 1997.

[146] N. Kinto, M. Iwamoto, M. Enomoto-Iwamoto et al., "Fibroblasts expressing Sonic hedgehog induce osteoblast differentiation and ectopic bone formation," FEBS Letters, vol. 404, no. 2-3, pp. 319-323, 1997.

[147] S. Spinella-Jaegle, G. Rawadi, S. Kawai et al., "Sonic hedgehog increases the commitment of pluripotent mesenchymal cells into the osteoblastic lineage and abolishes adipocytic differentiation," Journal of Cell Science, vol. 114, no. 11, pp. 2085-2094, 2001.

[148] G. van der Horst, H. Farih-Sips, C. W. G. M. Löwik, and M. Karperien, "Hedgehog stimulates only osteoblastic differentiation of undifferentiated KS483 cells," Bone, vol. 33, no. 6, pp. 899-910, 2003. 
[149] T. Aghaloo, C. M. Cowan, Y.-F. Chou et al., "Nell-1-induced bone regeneration in calvarial defects," American Journal of Pathology, vol. 169, no. 3, pp. 903-915, 2006.

[150] K. Ting, H. Vastardis, J. B. Mulliken et al., "Human NELL-1 expressed in unilateral coronal synostosis," Journal of Bone and Mineral Research, vol. 14, no. 1, pp. 80-89, 1999.

[151] X. Zhang, J. Zara, R. K. Siu, K. Ting, and C. Soo, "The role of NELL-1, a growth factor associated with craniosynostosis, in promoting bone regeneration," Journal of Dental Research, vol. 89, no. 9, pp. 865-878, 2010.

[152] X. Zhang, S. Kuroda, D. Carpenter et al., "Craniosynostosis in transgenic mice overexpressing Nell-1," Journal of Clinical Investigation, vol. 110, no. 6, pp. 861-870, 2002.

[153] X. Zhang, K. Ting, D. Pathmanathan et al., "Calvarial cleidocraniodysplasia-like defects with ENU-induced Nell-1 deficiency," Journal of Craniofacial Surgery, vol. 23, no. 1, pp. 6166, 2012.

[154] S. S. Lu, X. Zhang, C. Soo et al., "The osteoinductive properties of Nell-1 in a rat spinal fusion model," Spine Journal, vol. 7, no. 1, pp. 50-60, 2007.

[155] R. K. Siu, S. S. Lu, W. Li et al., "Nell-1 protein promotes bone formation in a sheep spinal fusion model," Tissue Engineering A, vol. 17, no. 7-8, pp. 1123-1135, 2011.

[156] W. Li, J. N. Zara, R. K. Siu et al., "Nell-1 enhances bone regeneration in a rat critical-sized femoral segmental defect model," Plastic and Reconstructive Surgery, vol. 127, no. 2, pp. 580-587, 2011.

[157] M. Lee, W. Li, R. K. Siu et al., "Biomimetic apatite-coated alginate/chitosan microparticles as osteogenic protein carriers," Biomaterials, vol. 30, no. 30, pp. 6094-6101, 2009.

[158] W. Li, M. Lee, J. Whang et al., "Delivery of lyophilized nell-1 in a rat spinal fusion model," Tissue Engineering A, vol. 16, no. 9, pp. 2861-2870, 2010.

[159] J. Shen, W. Aaron, J. Chung et al., "NELL-1 promotes cell adhesion and differentiation via Integrinbetal," Journal of Cellular Biochemistry, vol. 113, no. 12, pp. 3620-3628, 2012.

[160] F. Chen, B. Walder, A. W. James et al., "NELL-1-dependent mineralisation of Saos-2 human osteosarcoma cells is mediated via c-Jun N-terminal kinase pathway activation," International Orthopaedics, vol. 36, no. 10, pp. 2181-2187, 2012.

[161] A. W. James et al., "A new mode of action of Nell-1 protein via potentiation of Canonical Wnt signaling," Conferenece (Wnt '11), Los Angeles, Ca, USA, 2011.

[162] C. M. Cowan, X. Zhangb, A. W. James et al., "NELL-1 increases pre-osteoblast mineralization using both phosphate transporter Pit1 and Pit2, Biochemical and Biophysical Research Communications, vol. 422, no. 3, pp. 351-357, 2012.

[163] J. Kwak, J. N. Zara, M. Chiang et al., "NELL-1 injection maintains long-bone quantity and quality in an ovariectomyinduced osteoporotic senile rat model," Tissue Engineering A, vol. 19, no. 3-4, pp. 426-436, 2013.

[164] J. M. Wozney, V. Rosen, A. J. Celeste et al., "Novel regulators of bone formation: molecular clones and activities," Science, vol. 242, no. 4885, pp. 1528-1534, 1988.

[165] D. Chen, M. Zhao, and G. R. Mundy, "Bone morphogenetic proteins," Growth Factors, vol. 22, no. 4, pp. 233-241, 2004.

[166] B. Bragdon, O. Moseychuk, S. Saldanha, D. King, J. Julian, and A. Nohe, "Bone morphogenetic proteins: a critical review," Cellular Signalling, vol. 23, no. 4, pp. 609-620, 2011.

[167] M. O. Freire, H.-K. You, J.-K. Kook, J.-H. Choi, and H. H. Zadeh, "Antibody-mediated osseous regeneration: a novel strategy for bioengineering bone by immobilized anti-bone morphogenetic protein-2 antibodies," Tissue Engineering A, vol. 17, no. 23-24, pp. 2911-2918, 2011.

[168] G. E. Friedlaender, C. R. Perry, J. D. Cole et al., "Osteogenic protein-1 (bone morphogenetic protein-7) in the treatment of tibial nonunions," The Journal of Bone and Joint Surgery, vol. 83, no. 2, pp. S151-158, 2001.

[169] K. Miyazono, S. Maeda, and T. Imamura, "BMP receptor signaling: transcriptional targets, regulation of signals, and signaling cross-talk," Cytokine and Growth Factor Reviews, vol. 16, no. 3, pp. 251-263, 2005.

[170] A. Nohe, E. Keating, P. Knaus, and N. O. Petersen, "Signal transduction of bone morphogenetic protein receptors," Cellular Signalling, vol. 16, no. 3, pp. 291-299, 2004.

[171] R. Nishimura, K. Hata, T. Matsubara, M. Wakabayashi, and T. Yoneda, "Regulation of bone and cartilage development by network between BMP signalling and transcription factors," Journal of Biochemistry, vol. 151, no. 3, pp. 247-254, 2012.

[172] X. Li and X. Cao, "BMP signaling and skeletogenesis," Annals of the New York Academy of Sciences, vol. 1068, no. 1, pp. 26-40, 2006.

[173] K. Hata, R. Nishimura, F. Ikeda et al., "Differential roles of Smad1 and p38 kinase in regulation of peroxisome proliferatoractivating receptor $\gamma$ during bone morphogenetic protein 2induced adipogenesis," Molecular Biology of the Cell, vol. 14, no. 2, pp. 545-555, 2003.

[174] W. Jin, T. Takagi, S.-N. Kanesashi et al., "Schnurri-2 controls BMP-dependent adipogenesis via interaction with Smad proteins," Developmental Cell, vol. 10, no. 4, pp. 461-471, 2006.

[175] R. R. Bowers and M. D. Lane, "A role for bone morphogenetic protein- 4 in adipocyte development," Cell Cycle, vol. 6, no. 4, pp. 385-389, 2007

[176] R. R. Bowers, J. W. Kim, T. C. Otto, and M. D. Lane, "Stable stem cell commitment to the adipocyte lineage by inhibition of DNA methylation: role of the BMP-4 gene," Proceedings of the National Academy of Sciences of the United States of America, vol. 103, no. 35, pp. 13022-13027, 2006.

[177] S. Herzig and C. Wolfrum, "Brown and white fat: from signaling to disease," Biochim Biophys Acta, vol. 1831, no. 5, p. 895, 2013.

[178] R. Hao, L. Yuan, N. Zhang et al., "Brown adipose tissue: distribution and influencing factors on FDG PET/CT scan," Journal of Pediatric Endocrinology and Metabolism, vol. 25, no. 3-4, pp. 233-237, 2012.

[179] S. W. Qian, Y. Tang, X. Li et al., "BMP4-mediated brown fatlike changes in white adipose tissue alter glucose and energy homeostasis," Proceedings of the National Academy of Sciences of the United States of America, vol. 110, no. 9, pp. E798-E807, 2013.

[180] M. Ahrens, T. Ankenbauer, D. Schroder, A. Hollnagel, H. Mayer, and G. Gross, "Expression of human bone morphogenetic proteins- 2 or -4 in murine mesenchymal progenitor $\mathrm{C} 3 \mathrm{H} 10 \mathrm{~T}$ $1 / 2$ cells induces differentiation into distinct mesenchymal cell lineages," DNA and Cell Biology, vol. 12, no. 10, pp. 871-880, 1993.

[181] Y. Mishina, M. W. Starbuck, M. A. Gentile et al., "Bone morphogenetic protein type IA receptor signaling regulates postnatal osteoblast function and bone remodeling," The Journal of Biological Chemistry, vol. 279, no. 26, pp. 27560-27566, 2004.

[182] M. Okamoto, J. Murai, H. Yoshikawa, and N. Tsumaki, "Bone morphogenetic proteins in bone stimulate osteoclasts and osteoblasts during bone development," Journal of Bone and Mineral Research, vol. 21, no. 7, pp. 1022-1033, 2006. 
[183] E. Gazzerro, A. Smerdel-Ramoya, S. Zanotti et al., "Conditional deletion of gremlin causes a transient increase in bone formation and bone mass," The Journal of Biological Chemistry, vol. 282, no. 43, pp. 31549-31557, 2007.

[184] E. Gazzerro, R. C. Pereira, V. Jorgetti, S. Olson, A. N. Economides, and E. Canalis, "Skeletal overexpression of gremlin impairs bone formation and causes osteopenia," Endocrinology, vol. 146, no. 2, pp. 655-665, 2005.

[185] S. W. Davis and S. A. Camper, "Noggin regulates Bmp4 activity during pituitary induction," Developmental Biology, vol. 305, no. 1, pp. 145-160, 2007.

[186] W. Zhu, J. Kim, C. Cheng et al., "Noggin regulation of bone morphogenetic protein (BMP) $2 / 7$ heterodimer activity in vitro," Bone, vol. 39, no. 1, pp. 61-71, 2006.

[187] C. Cheng, "Osteogenic activity of the fourteen types of human bone morphogenetic proteins (BMPs)," Journal of Bone and Joint Surgery A, vol. 85, no. 8, pp. 1544-1552, 2004.

[188] M. Suzawa, Y. Takeuchi, S. Fukumoto et al., "Extracellular matrix-associated bone morphogenetic proteins are essential for differentiation of murine osteoblastic cells in vitro," Endocrinology, vol. 140, no. 5, pp. 2125-2133, 1999.

[189] P. Ducy and G. Karsenty, "The family of bone morphogenetic proteins," Kidney International, vol. 57, no. 6, pp. 2207-2214, 2000.

[190] J. Reid, H. M. Gilmour, and S. Holt, "Primary non-specific ulcer of the small intestine," Journal of the Royal College of Surgeons of Edinburgh, vol. 27, no. 4, pp. 228-232, 1982.

[191] M. Varkey, C. Kucharski, T. Haque, W. Sebald, and H. Uludağ, "In vitro osteogenic response of rat bone marrow cells to bFGF and BMP-2 treatments," Clinical Orthopaedics and Related Research, no. 443, pp. 113-123, 2006.

[192] K. Partridge, X. Yang, N. M. P. Clarke et al., "Adenoviral BMP-2 gene transfer in mesenchymal stem cells: In vitro and in vivo bone formation on biodegradable polymer scaffolds," Biochemical and Biophysical Research Communications, vol. 292, no. 1, pp. 144-152, 2002.

[193] F. Wegman, A. Bijenhof, L. Schuijff, F. C. Oner, W. J. Dhert, and J. Alblas, "Osteogenic differentiation as a result of BMP-2 plasmid DNA based gene therapy in vitro and in vivo," European Cells \& Materials, vol. 21, pp. 230-242, 2011.

[194] K.-H. Park, H. Kim, S. Moon, and K. Na, "Bone morphogenic protein-2 (BMP-2) loaded nanoparticles mixed with human mesenchymal stem cell in fibrin hydrogel for bone tissue engineering," Journal of Bioscience and Bioengineering, vol. 108, no. 6, pp. 530-537, 2009.

[195] Y. Tang, W. Tang, Y. Lin et al., "Combination of bone tissue engineering and BMP-2 gene transfection promotes bone healing in osteoporotic rats," Cell Biology International, vol. 32, no. 9, pp. 1150-1157, 2008.

[196] D. H. R. Kempen, L. Lu, T. E. Hefferan et al., "Retention of in vitro and in vivo BMP-2 bioactivities in sustained delivery vehicles for bone tissue engineering," Biomaterials, vol. 29, no. 22, pp. 3245-3252, 2008.

[197] S.-L. Cheng, J. Lou, N. M. Wright, C.-F. Lai, L. V. Avioli, and K. D. Riew, "In vitro and in vivo induction of bone formation using a recombinant adenoviral vector carrying the human BMP-2 gene," Calcified Tissue International, vol. 68, no. 2, pp. 87-94, 2001.

[198] D. Noël, D. Gazit, C. Bouquet et al., "Short-term BMP-2 expression is sufficient for in vivo osteochondral differentiation of mesenchymal stem cells," Stem Cells, vol. 22, no. 1, pp. 74-85, 2004.
[199] A. M. Osyczka, D. L. Diefenderfer, G. Bhargave, and P. S. Leboy, "Different effects of BMP-2 on marrow stromal cells from human and rat bone," Cells Tissues Organs, vol. 176, no. 1-3, pp. 109-119, 2004.

[200] D. L. Deifenderfer, A. M. Osyczka, G. C. Reilly, and P. S. Leboy, "BMP responsiveness in human mesenchymal stem cells," Connective Tissue Research, vol. 44, no. 1, pp. 305-311, 2003.

[201] C. Chen, H. Uludağ, Z. Wang, and H. Jiang, "Noggin suppression decreases BMP-2-induced osteogenesis of human bone marrow-derived mesenchymal stem cells in vitro," Journal of Cellular Biochemistry, vol. 113, no. 12, pp. 3672-3680, 2012.

[202] S. Rahman, P. J. Czernik, Y. Lu, and B. Lecka-Czernik, “ $\beta$ catenin directly sequesters adipocytic and insulin sensitizing activities but not osteoblastic activity of PPAR $\gamma 2$ in marrow mesenchymal stem cells," PLoS ONE, vol. 7, no. 12, Article ID e51746.

[203] S. Yakar, H. Kim, H. Zhao et al., "The growth hormone-insulin like growth factor axis revisited: lessons from IGF-1 and IGF-1 receptor gene targeting," Pediatric Nephrology, vol. 20, no. 3, pp. 251-254, 2005.

[204] A. Giustina, G. Mazziotti, and E. Canalis, "Growth hormone, insulin-like growth factors, and the skeleton," Endocrine Reviews, vol. 29, no. 5, pp. 535-559, 2008.

[205] C. Livingstone, "Insulin-like growth factor-I (IGF-I) and clinical nutrition," Clinical Science, vol. 125, no. 6, pp. 265-280, 2013.

[206] M. Kawai and C. J. Rosen, "Insulin-like growth factor-I and bone: lessons from mice and men," Pediatric Nephrology, vol. 24, no. 7, pp. 1277-1285, 2009.

[207] K. E. Govoni, "Insulin-like growth factor-I molecular pathways in osteoblasts: potential targets for pharmacological manipulation," Current Molecular Pharmacology, vol. 5, no. 2, pp. 143152, 2012.

[208] X.-D. Peng, P.-Z. Xu, M.-L. Chen et al., "Dwarfism, impaired skin development, skeletal muscle atrophy, delayed bone development, and impeded adipogenesis in mice lacking Aktl and Akt2," Genes and Development, vol. 17, no. 11, pp. 1352-1365, 2003.

[209] N. Ghosh-Choudhury, S. L. Abboud, R. Nishimura, A. Celeste, L. Mahimainathan, and G. G. Choudhury, "Requirement of BMP-2-induced phosphatidylinositol 3-kinase and Akt serine/threonine kinase in osteoblast differentiation and Smaddependent BMP-2 gene transcription," The Journal of Biological Chemistry, vol. 277, no. 36, pp. 33361-33368, 2002.

[210] L. Xian, X. Wu, L. Pang et al., "Matrix IGF-1 maintains bone mass by activation of mTOR in mesenchymal stem cells," Nature Medicine, vol. 18, no. 7, pp. 1095-1101, 2012.

[211] D. D. Bikle and Y. Wang, "Insulin like growth factor-I: a critical mediator of the skeletal response to parathyroid hormone," Current Molecular Pharmacology, vol. 5, no. 2, pp. 135-142, 2012.

[212] A. Mukherjee and P. Rotwein, "Insulin-like growth factor binding protein-5 in osteogenesis: facilitator or inhibitor?" Growth Hormone and IGF Research, vol. 17, no. 3, pp. 179-185, 2007.

[213] R. C. Mccarty, S. Gronthos, A. C. Zannettino, B. K. Foster, and C. J. Xian, "Characterisation and developmental potential of ovine bone marrow derived mesenchymal stem cells," Journal of Cellular Physiology, vol. 219, no. 2, pp. 324-333, 2009.

[214] J. Chen, K. Yuan, X. Mao et al., "Serum response factor regulates bone formation via IGF-1 and Runx2 signals," Journal of Bone and Mineral Research, vol. 27, no. 8, pp. 1659-1668, 2012. 
[215] B. Levi, A. W. James, D. C. Wan, J. P. Glotzbach, G. W. Commons, and M. T. Longaker, "Regulation of human adiposederived stromal cell osteogenic differentiation by insulin-like growth factor- 1 and platelet-derived growth factor- $\alpha$," Plastic and Reconstructive Surgery, vol. 126, no. 1, pp. 41-52, 2010.

[216] S. Kumar and S. Ponnazhagan, "Mobilization of bone marrow mesenchymal stem cells in vivo augments bone healing in a mouse model of segmental bone defect," Bone, vol. 50, no. 4 , pp. 1012-1018, 2012.

[217] A. Bernstein, H. O. Mayr, and R. Hube, "Can bone healing in distraction osteogenesis be accelerated by local application of IGF-1 and TGF- $\beta 1$ ??" Journal of Biomedical Materials Research $B$, vol. 92, no. 1, pp. 215-225, 2010.

[218] H.-W. Courtland, H. Sun, M. Beth-On et al., "Growth hormone mediates pubertal skeletal development independent of hepatic IGF-1 production," Journal of Bone and Mineral Research, vol. 26, no. 4, pp. 761-768, 2011.

[219] C. G. Tahimic, Y. Wang, and D. D. Bikle, "Anabolic effects of IGF-1 signaling on the skeleton," Frontiers in Endocrinology, vol. 4, article 6, 2013.

[220] M. Wabitsch, H. Hauner, E. Heinze, and W. M. Teller, “The role of growth hormone/insulin-like growth factors in adipocyte differentiation," Metabolism, vol. 44, no. 10, pp. 45-49, 1995.

[221] S. J. Yang, C. Y. Chen, G. D. Chang et al., "Activation of Akt by advanced glycation end products (AGEs): involvement of IGF1 receptor and caveolin-1," PLoS ONE, vol. 8, no. 3, Article ID e58100, 2013.

[222] A. W. James, A. Pan, M. Chiang et al., "A new function of Nell1 protein in repressing adipogenic differentiation," Biochemical and Biophysical Research Communications, vol. 411, no. 1, pp. 126-131, 2011.

[223] L. Xiao, T. Sobue, A. Esliger et al., "Disruption of the Fgf2 gene activates the adipogenic and suppresses the osteogenic program in mesenchymal marrow stromal stem cells," Bone, vol. 47, no. 2, pp. 360-370, 2010.

[224] L. Choy, J. Skillington, and R. Derynck, "Roles of autocrine TGF- $\beta$ receptor and Smad signaling in adipocyte differentiation," Journal of Cell Biology, vol. 149, no. 3, pp. 667-681, 2000.

[225] F. Ugarte, M. Ryser, S. Thieme et al., "Notch signaling enhances osteogenic differentiation while inhibiting adipogenesis in primary human bone marrow stromal cells," Experimental Hematology, vol. 37, no. 7, pp. 867.e1-875.e1, 2009.

[226] M. R. Byun, H. Jeong, S. J. Bae, A. R. Kim, E. S. Hwang, and J.-H. Hong, "TAZ is required for the osteogenic and anti-adipogenic activities of kaempferol," Bone, vol. 50, no. 1, pp. 364-372, 2012.

[227] S. Wang, J. Mu, Z. Fan et al., "Insulin-like growth factor 1 can promote the osteogenic differentiation and osteogenesis of stem cells from apical papilla," Stem Cell Research, vol. 8, no. 3, pp. 346-356, 2012.

[228] T. Teruel, A. M. Valverde, M. Benito, and M. Lorenzo, "Insulinlike growth factor I and insulin induce adipogenic-related gene expression in fetal brown adipocyte primary cultures," Biochemical Journal, vol. 319, no. 2, pp. 627-632, 1996.

[229] Y.-L. Huang, R.-F. Qiu, W.-Y. Mai et al., "Effects of insulin-like growth factor-1 on the properties of mesenchymal stem cells in vitro," Journal of Zhejiang University B, vol. 13, no. 1, pp. 20-28, 2012. 

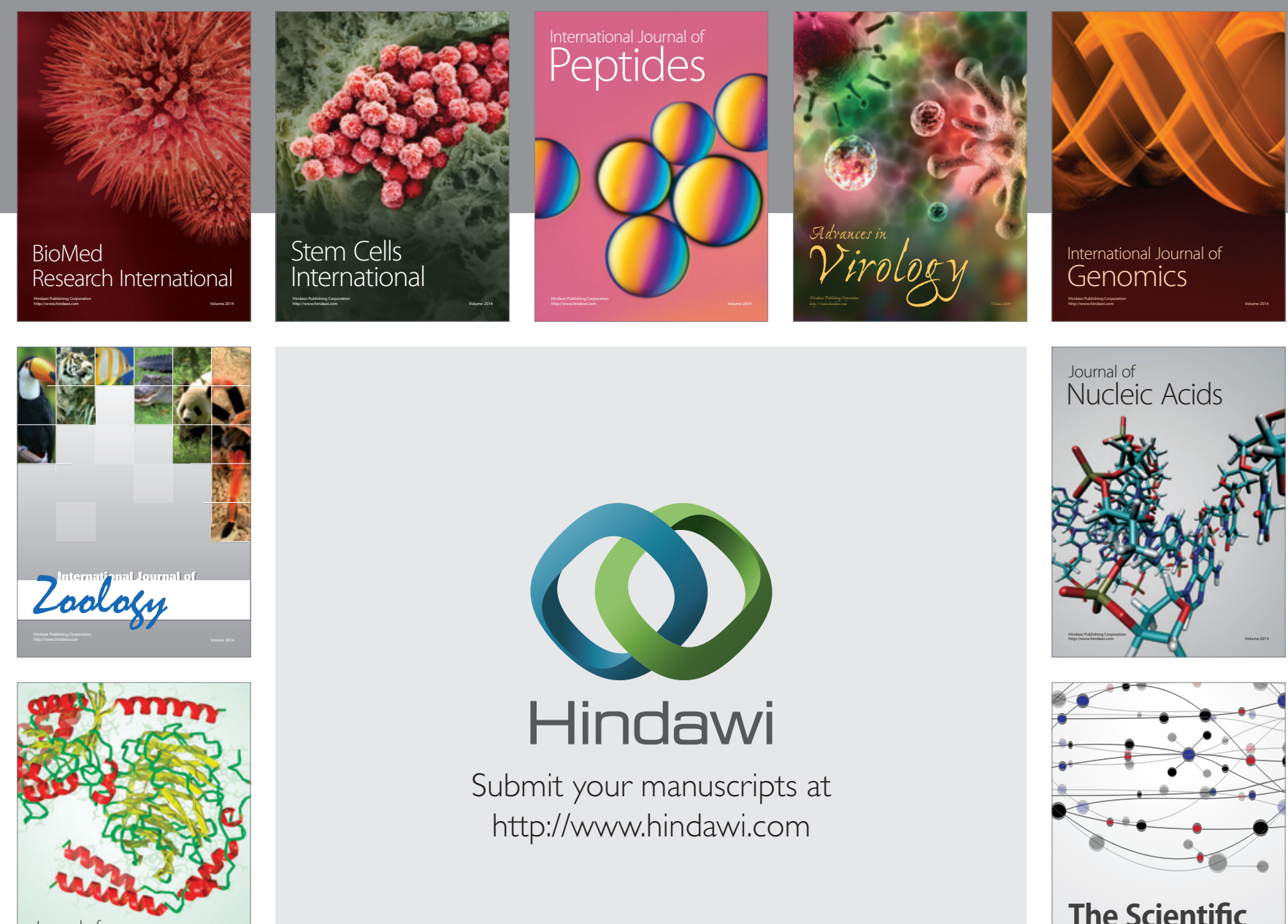

Submit your manuscripts at

http://www.hindawi.com

Journal of
Signal Transduction
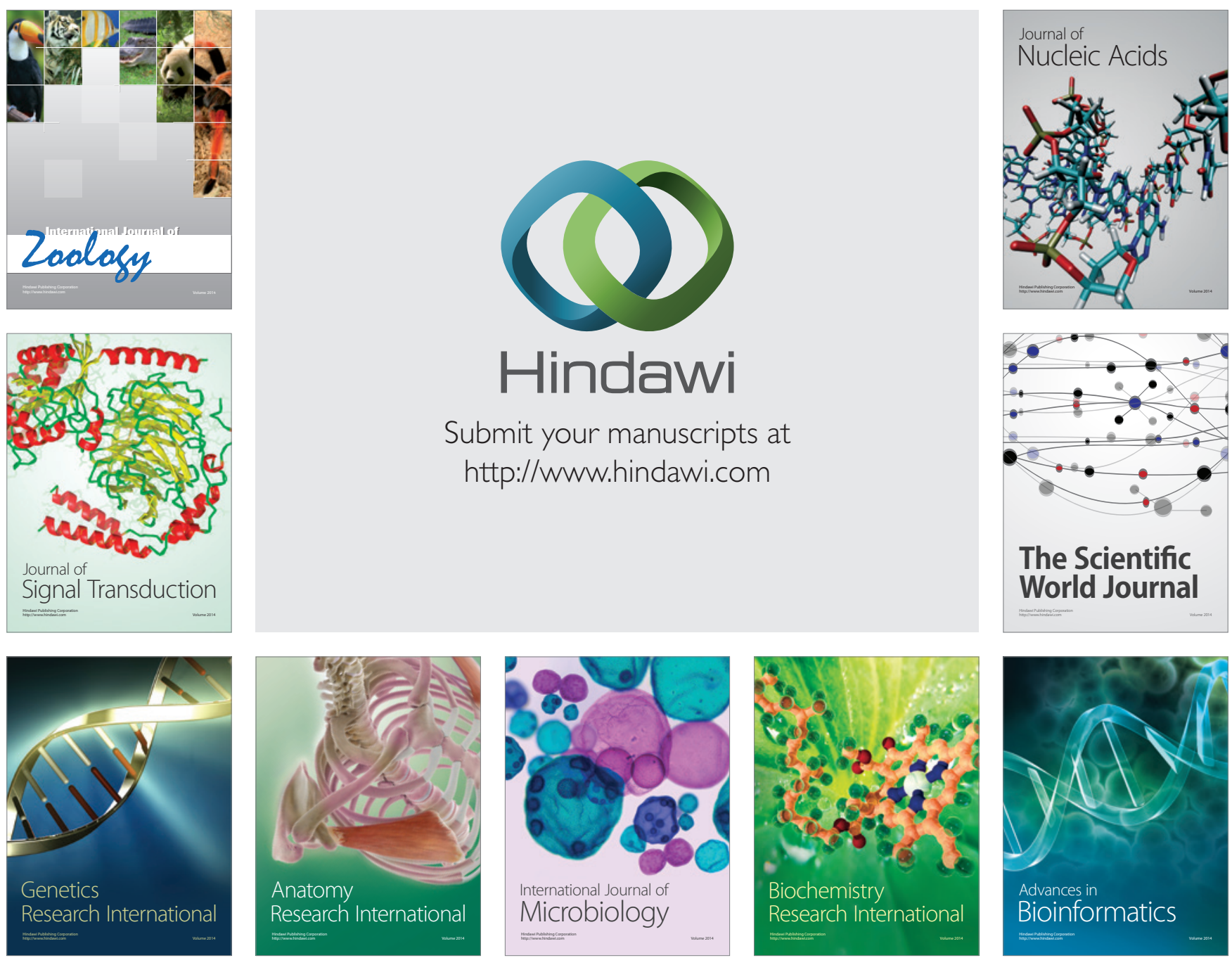

The Scientific World Journal
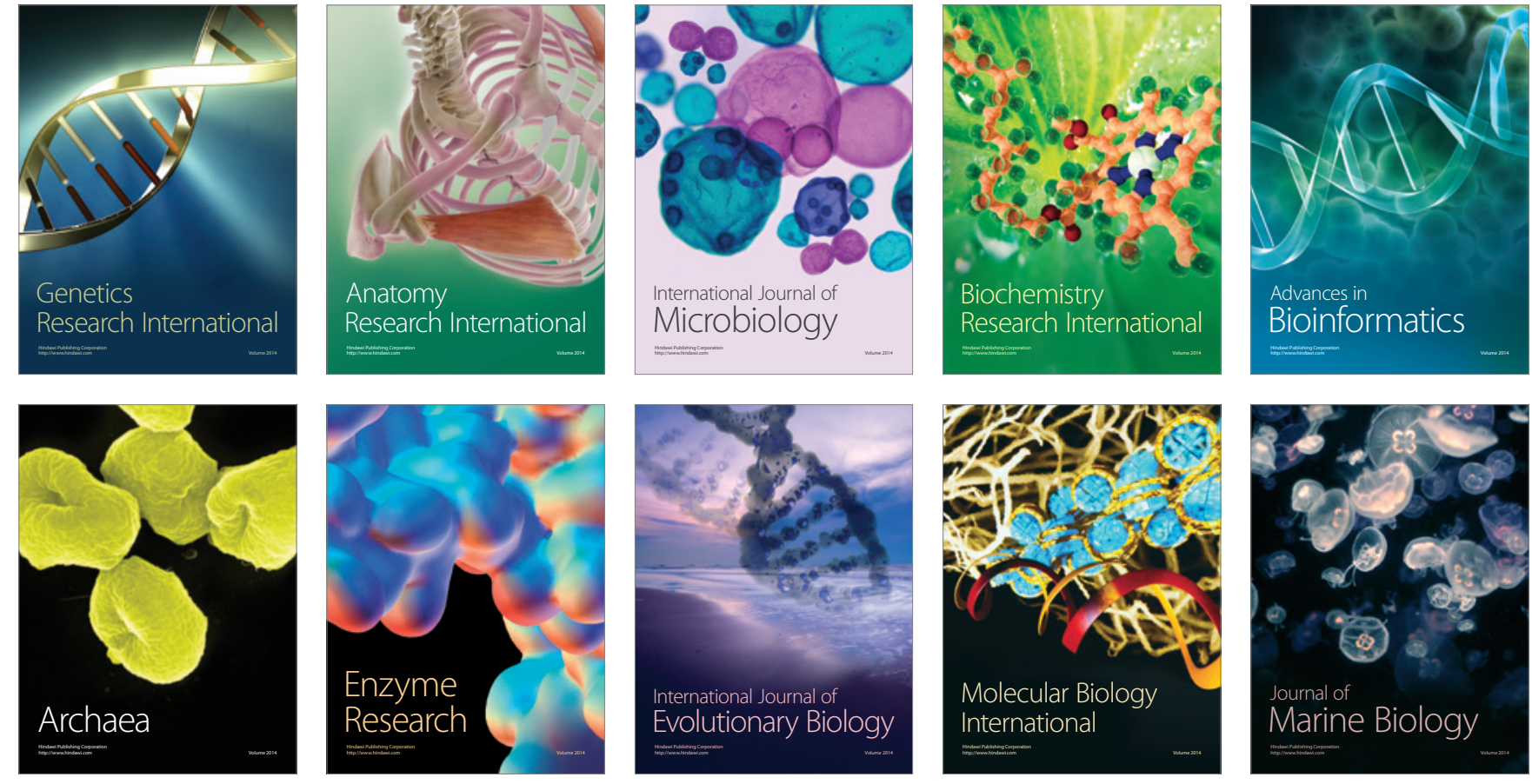